\title{
The bargaining-sales-delegation game
}

\section{Luciano Fanti • Luca Gori • Mauro Sodini}

\begin{abstract}
This article revisits the managerial delegation literature led by Vickers (1985), Fershtman and Judd (1987) and Sklivas (1987) by introducing a bargaining mechanism between owners and managers over managerial contracts. It shows that the degree of bargaining interacts with the extent of product differentiation in determining whether the sub-game perfect Nash equilibrium is sales delegation (S) or profit maximisation (PM). In contrast with the classical result, no sales delegation emerges and the typical prisoner's dilemma of the managerial delegation literature is solved. This holds in both contexts of Cournot and Bertrand rivalries. The article also provides results for the more general cases with heterogeneous managerial bargaining power and endogenous decisions of the owners regarding the bargaining power of the manager that should be or not be hired in a firm.
\end{abstract}

Keywords Bargaining; Price competition; Quantity competition; Sales delegation

JEL Classification D43; J53; L1

L. Fanti

Department of Economics and Management, University of Pisa, Via Cosimo Ridolfi, 10, I-56124 Pisa (PI), Italy e-mail: luciano.fanti@unipi.it

tel.: +390502216 369; fax: +390502210603

L. Gori (corresponding author)

Department of Political Science, University of Genoa, Piazzale E. Brignole, 3a, I-16125 Genoa (GE), Italy

e-mail: luca.gori@unige.it or dr. luca.gori@gmail.com

tel.: +3901020995 03; fax: +390102095536

M. Sodini

Department of Economics and Management, University of Pisa, Via Cosimo Ridolfi, 10, I-56124 Pisa (PI), Italy e-mail: mauro.sodinieunipi.it

tel.: +390502216 234; fax: +39050 2210603 


\section{Introduction}

Although traditional economic theories have solely regarded a firm as a profit-maximising entity, ${ }^{1}$ for a long time separation of ownership and control has been largely observed in several firms, especially with regard to large corporations. By adopting a modern game theoretic approach, the Industrial Organisation literature has argued - since the mid-1980s - that owners have the possibility to hire a manager and delegate output decisions to him. According with this view, the remuneration scheme of the manager (which is only partially based on profits) can be used as a strategic instrument. Rather paradoxically, this means that owners advise their managers to a partially non-profit-maximising behaviour to maximise their own profitability. ${ }^{2}$

The pioneering and most recognised articles analysing this issue are the delegation models by Vickers (1985), Fershtman and Judd (1987) and Sklivas (1987) (VFJS, henceforth). In particular, Vickers (1985) considers a managerial compensation scheme that adds an incentive for sales to profits, whereas Fershtman and Judd (1987) and Sklivas (1987) essentially share the same model of Vickers (1985) but they use revenues (rather than sales) as an additional incentive device. Empirical evidence shows that the use of managerial compensations considering both firm's profit and firm's size as measured by sales or revenues are empirically relevant, as pointed out, for example, by Jensen and Murphy (1990) and Lambert et al. (1991).

VFJS share the same result, which is the cornerstone of the managerial delegation literature: in a duopoly with quantity-setting firms, profits of the owner who designs a contract based on the maximisation of profits and sales (or revenues) are higher than profits of his rival, who just prescribes his manager to maximise pure profits. As this is a dominant strategy, the owner is induced to include incentives for sales (revenue) in her manager's contract. Therefore, the choice of delegating to external managers how to behave in the product market is the unique sub-game perfect Nash equilibrium (SPNE, henceforth) of the managerial delegation game. However, at equilibrium, profits of both firms (owners) are lower than in a standard Cournot game, so that a prisoner's dilemma situation emerges. ${ }^{3}$

Under price competition, the above result becomes the opposite. Indeed, the crucial difference between price competition and quantity competition is that the reaction curves in prices (resp. quantities) slope upward (resp. downward). This means that with price setting firms, the greater a firm's expectation about rival's price, the higher the price. In fact, at equilibrium owners penalise managers on sales at the margin, so that managers will price less aggressively than under profit maximisation. Consequently, the equilibrium price with sales delegation will be higher than the equilibrium price under profit maximisation. In the words of Fershtman and Judd (1987) "in the price competition case, incentive equilibrium essentially pushes the price toward the monopolistic price" and thus hiring managers is of mutual advantage to firms. To sum up, in a duopoly where price is the strategic variable the VFJS's main finding is that of choosing sales delegation as the dominant strategy, which is also pay-off dominating. Therefore, the managerial delegation game is no longer a prisoner's dilemma also under price competition.

For further comparisons, we define these cornerstone results both under quantity and price competition as the VFJS's result. We have to note that these observations about the ranking of equilibrium profits in the two competing cases hold when products are substitutes. Conversely, when products are complements the reaction curves in prices (resp. quantities) slope downward (resp. upward). Therefore, with product complementarity under price (resp. quantity) competition the incentive equilibrium is pay-off dominated by the profit-maximising equilibrium (resp. profit-

\footnotetext{
${ }^{1}$ This hypothesis has been often criticised in the economic literature (Baumol, 1958; Simon, 1964; Williamson, 1964; Leibenstein, 1979).

${ }^{2}$ In fact, this finding is often referred to as the profit-maximisation paradox (van Witteloostuijn, 1998).

3 Mujumdar and Pal (2007) examine the nature of optimal managerial incentive contracts in a duopoly where competition between managers in the output market occur in a dynamic environment; whereas Berr (2011) shows that the prisoners' dilemma of VFJS can be overcome by adequately designing multiplicative incentive delegation schemes.
} 
dominates the profit-maximising equilibrium). Although the present article only focuses on sales delegation as in the original VFJS's approach, we note that, subsequently, the literature on this issue has also proposed new kinds of managerial contracts. (1) A contract based on a weighted sum of firm's own profit and rival's profit (relative performance or profit delegation) (Salas Fumás, 1992; Miller and Pazgal, 2002). (2) A contract based on a combination of its own profit and market share (market share delegation) (Jansen et al., 2007; Ritz, 2008). Despite this, also with these different types of incentive schemes, the essence of the traditional VFJS's result seems to be unchallenged.

The above-mentioned literature on delegation games typically assumed that the owner chooses the type of bonus and the relevant weight in order to maximise his own profits, and makes a corresponding take-it-or-leave-it offer to the manager (Inderst, 2002). However, a modern view of the firm argues that in general "decisions by firms look more like a compromise between conflicting parties than maximisation of a single objective function. Explicitly or implicitly a process of bargaining occurs continuously, and the decision that is finally taken is the result of this bargaining process." (Fershtman, 1985, 245). According to this view, decisions in a firm are taken based on a bargaining process (Cyert and March, 1963; Aoki, 1980). Then, a branch of the managerial delegation literature exploring bargaining issues is emerged (bargaining-delegation game literature), since the seminal article by Fershtman (1985), who assumes that a firm chooses between profit maximisation or the adoption of a "compromise" rule with its managers. This rule is such that the owner (who maximises profits) and the manager (who maximises sales) make output decisions cooperatively. In Fershtman (1985) as well as in the subsequent related literature, cooperative bargaining is modelled by using an axiomatic approach (Roth, 1979) and the Nash solution (Nash, 1950) as the necessary outcome of the bargaining.

It is important to recognise that also for financial economists the dominant paradigm in the explanation of the manager's pay-setting process is the "arm's-length bargaining" approach. According to this view, pay arrangements are the product of a bargaining between executives attempting to get the possible deal for themselves and boards seeking to get the best possible deal for shareholders (Bebchuk and Fried, 2004). Note that the assumption that managers' pay is determined by an arm's-length bargaining between boards and executives has also been the basis for the corporate law rules governing the subject. In particular, in large public corporations in which ownership is widespread such as in U.S., the board of directors is responsible for bargaining the compensation of the CEO and other top executives and Securities and Exchange Commission (SEC) as well as tax rules and court decisions prescribe (for a better protection of shareholders' interests), the independence ${ }^{4}$ of the board's members. The essence of the "arm's-length bargaining" approach is then captured by our formulation of a bargaining mechanism between owners and managers over managerial contracts, as shown later in this article. By passing, we note that the recent dramatic increase in managers' pay (Bebchuk and Grinstein, 2005) may be due because several boards have employed compensation arrangements penalising shareholders' interests. The issue of whether and how common compensation arrangements may be not consistent with the "arm's-length bargaining" approach, for instance because board's members have been sympathetic to managers, insufficiently motivated to bargain over compensation, or simply ineffectual in overseeing compensation (Bebchuk and Fried, 2004) is an interesting issue, but it is beyond of the scope of the article.

In the bargaining-delegation game branch of the literature, several models focus on wage bargaining, with the aim of questioning whether and how in a context with a bargaining between unions and managers delegation affects product market competition, depending upon the specifics of the managerial compensation scheme (Szymanski, 1994; Bughin, 1995; Merzoni, 2003). Van Witteloostuijn et al. (2007) have extended this literature by assuming that owner-shareholders negotiate with their managers about executive remuneration. Essentially, the work of van

\footnotetext{
${ }^{4}$ Members of the board involved in managers' pay setting are generally recognised to be independent if they have not been (formerly or currently) employees of the firm and they are not affiliated with the firm other than through their directorship (Bebchuk and Fried, 2004).
} 
Witteloostuijn et al. (2007) differs from that of Fershtman (1985) as the former explicitly models out the owner-manager bargaining on the incentive parameter of the managerial contract, ${ }^{5}$ whereas the latter assumes that the owner-manager bargaining is on output decisions.

Specifically, the model of van Witteloostuijn et al. (2007) is a two-stage delegation game in which owners-shareholders negotiate the incentive parameter on the managerial contract with managers in the first stage. ${ }^{6}$ The incentive parameter is publicly observable. The managerial contracts' disclosure obligation seems to be a typical feature of several modern corporate governance codes, introduced ever since the early 1990s in the UK and in the US and subsequently in several other countries. This principally aims to protect owner-shareholders against opportunistic behaviour by managers. Indeed, as noted by van Witteloostuijn et al. (2007), by the end of 2005 the number of countries adopting such codes had increased to more than 50. Subsequently, in the second stage each firm's manager engages a process of Cournot competition in the product market for a homogeneous good. Under sales delegation contracts, they show that if the bargaining power of the managers increases, equilibrium profits of every firm decreases and social welfare increases. In contexts of both quantity and price competition, Nakamura (2008a, 2008b) and Kamaga and Nakamura (2008) extend van Witteloostuijn et al. (2007) to the cases of differentiated goods, quadratic costs and sequential competition, respectively, to test the robustness of van Witteloostuijn et al. (2007) main findings. Although Nakamura (2008a), and Kamaga and Nakamura (2008) obtain a result similar to van Witteloostuijn et al. (2007), Nakamura (2008b) finds that equilibrium social welfare deteriorates with both kinds of competition in the product market if the relative bargaining power of managers is sufficiently large. ${ }^{7}$ Furthermore, Wang et al. (2008) explore the effects of owner-manager bargaining over the incentive parameter on the managerial contract on strategic trade policies, showing that the introduction of manager's bargaining leads to a decrease in the export subsidy and optimal tariff in different trade models. Later, Nakamura (2011) introduces a bargaining owner-manager in a three-firm Cournot industry with asymmetric costs that accounts for a (horizontal) merger process with managerial delegation contracts à la VFJS. In that context, he shows that a firm's internal organisation (i.e., whether a manager is hired or not) is responsible for different kinds of antitrust policies in comparison with the case without the bargaining. In addition, Nakamura (2012) generalises van Witteloostuijn et al. (2007) by considering a differentiated oligopoly with a general number of (symmetric) quantity-setting or price-setting firms. He confirms that - at the equilibrium - firms' profits decrease and social welfare increases when the bargaining power of the manager goes up. These results are shown for the cases of sales delegation and relative profit delegation contracts.

However, none of the previous works deals with the important issue of the endogenous equilibrium of the bargaining-delegation game. In this article, therefore, we fill this gap by investigating the existence and uniqueness of the SPNE in a linear ${ }^{8}$ duopoly with horizontal product differentiation, where - different from VFJS - owners and managers bargain over executive remuneration with sales delegation. In sharp contrast to the traditional VFJS's result, the present article shows that under quantity and price competition the choice of delegating the output decision to managers is no longer the unique SPNE of the game: multiple SPNEs and the choice of profitmaximising behaviour as the unique SPNE may occur. This depends on the relative weight of the bargaining power of managers and the extent of product differentiation. Moreover, the typical

\footnotetext{
${ }^{5}$ This also holds with regard to the comparison with the works of Szymanski (1994) and Bughin (1995), who added a union-manager bargaining over wages to the Fershtman's (1985) owner-manager bargaining on output.

${ }^{6}$ That is, the owner (who wants to maximise profits) and (candidate) manager (who tries to optimise the bonus) bargain over the incentive parameter.

${ }^{7}$ This is due to the quadratic cost function, which - different from the linear cost function - causes a decrease in the producer surplus larger than the increase in the consumer surplus when the relative bargaining power of a manager becomes high enough.

${ }^{8}$ For comparison purposes with VFJS, we consider sales delegation and linear demand and cost functions. The analysis of a model with different functional forms as well as with different kinds of managerial contracts (such as the "relative performance" and the "market share" incentive schemes is left to a future research agenda.
} 
prisoner's dilemma of VFJS may be solved. An important consequence of these findings is that one should question the wisdom of the previous managerial delegation literature. Specifically, owners may choose to do not delegate and this choice may be Pareto efficient. Moreover, we have also shown that the present result may be further enriched by taking account for 1) heterogeneity of managers' bargaining power, 2) endogenous decisions of the owners regarding the bargaining power of the manager that should be or not be hired in a firm.

The rest of the article proceeds as follows. Section 2 introduces a bargaining mechanism between owners and managers over the type of executive bonus by considering a duopoly with quantitysetting firms. Section 3 tackles the same issue in a duopoly with price-setting firms. Section 4 discusses the main results of the article and compares similarities and differences of the bargainingsales-delegation game in both cases of Cournot and Bertrand rivalries. Section 5 outlines the conclusions. Appendix A identifies another channel through which the results stated in the main text hold. Specifically, it relaxes the hypothesis of the existence of a bargaining owner-manager over managerial compensation at the bargaining stage, and assumes the existence of a board of directors that may not be as independent of managers' influences as the owners might wish and maximises (unilaterally) its own objective function at the contract stage of the game. This dependency is captured by following Laux and Mittendorf (2011). Appendix B generalises the results presented in the main text to the case of heterogeneous managerial bargaining power. Appendix C provides an analysis of Cournot and Bertrand duopolies with endogenous decisions of the owners regarding the bargaining power of managers they have to decide whether to hire or not to hire.

\section{The bargaining-sales-delegation game with quantity-setting firms}

We assume an economy with two types of agents: firms and consumers. The economy is bisectorial, i.e. there exist a competitive sector that produces the numeraire good $y$, and a duopolistic sector with firm 1 and firm 2 that produce differentiated products. Let $p_{i} \geq 0$ and $q_{i} \geq 0$ denote firm $i$ 's price and quantity, respectively, with $i=1,2$.

There exists a continuum of identical consumers who have preferences towards $q_{1}, q_{2}$ and $y$ represented by a separable utility function $V\left(q_{1}, q_{2}, y\right): \mathfrak{R}_{+}^{3} \rightarrow \mathfrak{R}_{+}$, which is linear in the numeraire good. The representative consumer maximises $V\left(q_{1}, q_{2}, y\right)=U\left(q_{1}, q_{2}\right)+y$ with respect to quantities subject to the budget constraint $p_{1} q_{1}+p_{2} q_{2}+y=M$, where $U\left(q_{1}, q_{2}\right): \mathfrak{R}_{+}^{2} \rightarrow \Re_{+}$is a twice continuously differentiable function and $M$ denotes the consumer's exogenous nominal income. This income is high enough to avoid the existence of corner solutions. As $V\left(q_{1}, q_{2}, y\right)$ is a separable function and it is linear in $y$, there are no income effects on the duopolistic sector. This implies that for a large enough level of income, the representative consumer's optimisation problem can be reduced to choose $q_{i}$ to maximise $U\left(q_{1}, q_{2}\right)-p_{1} q_{1}-p_{2} q_{2}+M$. Utility maximisation, therefore, yields the inverse demand functions (i.e., the price of good $i$ as a function of quantities): $p_{i}=\frac{\partial U\left(q_{i}, q_{j}\right)}{\partial q_{i}}$, for $q_{i}>0$ and $i=1,2, i \neq j$.

To proceed further with the analysis, we assume explicit demand functions for products of variety 1 and variety 2 . To this end, we take into account the usual specification of a quadratic utility to describe consumers' preferences as proposed by Dixit (1979) and subsequently used, amongst others, by Singh and Vives (1984), Häckner (2000), and Correa-López and Naylor (2004). An important feature of such a utility function is that it generates a system of linear demand functions. Therefore, we assume that preferences of the representative consumer over $q_{1}$ and $q_{2}$ are given by: 


$$
U\left(q_{1}, q_{2}\right)=q_{1}+q_{2}-\frac{1}{2}\left(q_{1}^{2}+q_{2}^{2}+2 d q_{1} q_{2}\right),
$$

where $-1 \leq d \leq 1$ represents the degree of horizontal product differentiation. ${ }^{9}$ Some clarifications on the parameter $d$ are now in order. If $d=0$, then products of variety 1 and variety 2 are independent between each other, i.e., each firm behaves as if it were a monopolist in its own market. If $d=1$ (resp. $d=-1$ ) then products of varieties 1 and 2 are perfect substitutes (resp. perfect complements). In contrast, $0<d<1 \quad(-1<d<0)$ reflects the case of imperfect substitutability (resp. imperfect complementarity) between products of both varieties.

The representative consumer maximises (1) with respect to $q_{1}$ and $q_{2}$ subject to the budget constraint $p_{1} q_{1}+p_{2} q_{2}+y=M$. Then, the linear inverse demand functions of product of variety $i$ is the following

$$
p_{i}=1-q_{i}-d q_{j}
$$

where $i=1,2, i \neq j$. By Following Correa-López and Naylor (2004), we assume that firm $i$ produces output of variety $i$ by using a technology with constant (marginal) returns to labour, that is $q_{i}=L_{i}$, where $L_{i}$ is the labour input. Firm 1 and firm 2 face the same (constant) average and marginal cost $0 \leq w<1$ for every unit of output produced. Therefore, firm $i$ 's cost function is linear and described by:

$$
C_{i}\left(q_{i}\right)=w L_{i}=w q_{i} .
$$

From now on, we fix $w=0$ without loss of generality. Therefore, profits of firm $i\left(\Pi_{i}\right)$ can be written as follows:

$$
\Pi_{i}=p_{i} q_{i} .
$$

By following the VFJS's approach, we assume that the owner of every firm hires a manager and delegates the output decision to him. Each manager receives a fixed salary and a bonus related to a weighted combination of firm's profits and other performance measures. Manager $i$ 's remuneration can be expressed as $\omega_{i}=\mathrm{A}_{i}+\mathrm{B}_{i} u_{i} \geq 0$ (full contract details), where $\mathrm{A}_{i} \geq 0$ is the fixed salary component in manager's compensation, $\mathrm{B}_{i} \geq 0$ is a constant, and $u_{i}$ is the utility of manager $i$. We set the fixed salary component of executive pay to zero throughout the article. However, it is important to point out that the results of this article are qualitatively the same if the bargaining owner-manager (as specified later on) included full contract details. We do not report this case here and analyse a model where $\mathrm{A}_{i}=0$ simply for analytical convenience. ${ }^{10}$ Then, we assume that the standard incentive contract is designed to weight firm's profit and sales (sales delegation). In particular, we follow the early formulation of the contract outlined by Vickers (1985) and subsequently adopted in several works, e.g. van Witteloostuijn et al. (2007) and Jansen et al. (2009), where the performance measure is the sales volume. ${ }^{11}$ Mathematically, the utility of manager $i$ takes the following form:

$$
u_{i}=\Pi_{i}+b_{i} q_{i} .
$$

where $b_{i}$ is the incentive parameter chosen by both the owner and manager of $i$ th firm in the bargaining stage. It may be positive or negative depending on whether the owner provides incentives or disincentives to the manager. If $b_{i}>0$ (resp. $b_{i}<0$ ) the manager becomes more (resp.

\footnotetext{
${ }^{9}$ If, at equal prices, consumers do not agree on which product is the preferred one then products are said to be horizontally differentiated. This is captured by the fact that consumers differ in their preferences over product's characteristics.

${ }^{10}$ It is also assumed that the remaining part of the manager's remuneration is negligible in comparison with the total cost of the firm, so that manager's pay $\left(\omega_{i}\right)$ does not enter in it.

${ }^{11}$ As is shown by Jansen et al. (2007), the combination of profits and revenues used by Fershtman and Judd (1987) and Sklivas (1987) can easily be rewritten as a combination of profits and sales volume.
} 
less) aggressive in the market. Of course, (5) holds when profits of firm $i$ are positive. If profits are negative, managers receive no bonus.

The present article focuses on the study of a game-theoretic delegation model à la VFJS. Then, we now clarify the logic of the setup we will follow here. Of course, the methodology used resembles the one adopted in VFJS's works. However, instead of the well-known two-stage delegation game where the nature of the bonus is exogenous, we consider a three-stage game where the nature of the bonus is endogenous. In the classical two-stage exogenous game, there exists the contract stage and the market stage. In the former, the owner of every firm chooses the incentive parameter (by maximising profits) to direct his manager in the product market. In the latter, the manager of every firm (by knowing the size and direction of the incentive parameter) strategically chooses the quantity (Cournot duopoly) or the price (Bertrand duopoly) to maximise his utility. Differently, the timing of our three-stage endogenous game with observable actions is detailed as follows. At stage 1 (the contract-bonus stage), firms strategically choose the nature of the bonus (i.e., pure profits or sales delegation). At stage 2 (the bargaining stage), owners and managers are engaged in a bargaining to choose executive remuneration, as in van Witteloostuijn et al. (2007). At stage 3 (the market stage), managers choose either the quantity (in the case of quantity-setting behaviour) or the price (in the case of price-setting behaviour). The game is solved by using the standard backward logic.

\subsection{Pure profit maximisation (PM)}

When the objective of both firms is standard profit maximisation, firms do not hire any managers $\left(b_{i}=0\right)$ and each owner chooses the quantity at the market stage. Alternatively, one may interpret pure profit maximisation as a situation in which each owner hires a manager and lets him behave just like a profit maximiser. Therefore, by using market demand (2), profit maximisation yields the usual reaction functions for firm 1 and firm 2, respectively, that is:

$$
\frac{\partial \Pi_{1}}{\partial q_{1}}=0 \Leftrightarrow q_{1}\left(q_{2}\right)=\frac{1-d q_{2}}{2},
$$

and

$$
\frac{\partial \Pi_{2}}{\partial q_{2}}=0 \Leftrightarrow q_{2}\left(q_{1}\right)=\frac{1-d q_{1}}{2} .
$$

From (6) and (7), it is clear that an increase in the degree of product differentiation (the parameter $d$ reduces) causes an increase in the quantity produced by both firms. The use of reaction functions (6) and (7) gives the following equilibrium values of quantity, market price and profits of $i$ th firm:

$$
\begin{aligned}
& q_{i}^{P M / P M}=\frac{1}{2+d}, \\
& p_{i}^{P M / P M}=\frac{1}{2+d},
\end{aligned}
$$

and

$$
\Pi_{i}^{P M / P M}=\frac{1}{(2+d)^{2}} .
$$

As is clear, when $d$ reduces (i.e., the extent of product differentiation increases) quantity, market price and profits increase.

\subsection{Sales delegation $(S)$}

We now assume that the owner of each firm hires a manager and delegates output decisions to him according with sales delegation contracts. The backward logic argument allows us to proceed as

follows. Given decisions taken in both the contract-bonus stage and bargaining stage, manager of 
firm $i$ maximises utility (5) with respect to $q_{i}$. Therefore, the reaction function of managers of firm 1 and firm 2 (as a function of rival's quantity and his how bonus) are given by:

$$
\frac{\partial u_{1}}{\partial q_{1}}=0 \Leftrightarrow q_{1}\left(q_{2}, b_{1}\right)=\frac{1-d q_{2}+b_{1}}{2}
$$

and

$$
\frac{\partial u_{2}}{\partial q_{2}}=0 \Leftrightarrow q_{2}\left(q_{1}, b_{2}\right)=\frac{1-d q_{1}+b_{2}}{2} .
$$

The degree of product differentiation plays the same role on quantities as in the case pure profits. With regard to the incentive parameter, the reaction functions (11) and (12) clearly show that if weight $b_{i}$ is positive (resp. negative), manager $i$ has an incentive to increase (resp. reduce) output. From (11) and (12), we definitely get quantities as function of both weights, that is:

$$
\bar{q}_{1}\left(b_{1}, b_{2}\right)=\frac{2\left(1+b_{1}\right)-d\left(1+b_{2}\right)}{(2-d)(2+d)}
$$

and

$$
\bar{q}_{2}\left(b_{1}, b_{2}\right)=\frac{2\left(1+b_{2}\right)-d\left(1+b_{1}\right)}{(2-d)(2+d)} .
$$

At the bargaining stage, the owner and the manager of every firm both choose managers' executive pay (type) by determining the incentive parameter. As these parties have conflicting interest, "it makes sense for them to bargain over the weight $\left[b_{i}\right]$ " (van Witteloostuijn, 2007). In particular, we assume that owner and manager of firm $i$ are engaged in a bargaining process that weights manager's utility and owners' profits. By following van Witteloostuijn (2007), it is assumed that all managers are homogeneous in terms of bargaining power and bonus preference, so that the bargaining power is equal. Then, by using (13) and (14) player $i$ maximises the following Nash product with respect to $b_{i}$ (Binmore et al., 1986):

$$
\mathrm{N}_{i}=u_{i}^{k} \Pi_{i}^{1-k}
$$

where $0 \leq k<1$ is the relative bargaining power of manager of firm $i$. The lower is $k$ the lower is the power of managers in fixing their own remuneration against the interest of shareholders. When $k=0$ (15) boils down to the standard VFJS case in which the owner is unilaterally involved in setting the weight of the bonus in the managerial contract. A justification for Eq. (15) is given by the fact that (since the early 1990s) several countries around the world have introduced codes of corporate governance (Aguilera and Cuervo-Cazurra, 2004), essentially "to protect ownershareholders against opportunistic behavior by managers." (van Witteloostuijn, 2007). This may have consequences with regard to decision-making processes designing managerial compensation and managerial compensation disclosure. With the formulation used in (15) we are implicitly assuming that if the bargaining power of the manager equals zero, each managers is rewarded on the basis of pure profits and then behaves just like a profit maximiser.

Therefore, the system of reaction functions in the bonus space are the following:

$$
\begin{aligned}
& \frac{\partial \mathrm{N}_{1}}{\partial b_{1}}=\frac{u_{1}\left(b_{1}, b_{2}\right)^{k} \Pi_{1}\left(b_{1}, b_{2}\right)^{1-k}\left\{\left[2-d\left(1+b_{2}\right)\right]\left[d^{2}+k\left(4-d^{2}\right)\right]-4\left(2-d^{2}\right) b_{1}\right\}}{\left[2\left(1+b_{1}\right)-d\left(1+b_{2}\right)\right]\left[2-b_{1}\left(2-d^{2}\right)-d(2+d)\right]}=0 \Leftrightarrow \\
& \Leftrightarrow b_{1}\left(b_{2}\right)=\frac{\left[2-d\left(1+b_{2}\right)\right]\left[d^{2}+k\left(4-d^{2}\right)\right]}{4\left(2-d^{2}\right)}
\end{aligned}
$$

and 


$$
\begin{aligned}
& \frac{\partial \mathrm{N}_{2}}{\partial b_{2}}=\frac{u_{2}\left(b_{1}, b_{2}\right)^{k} \Pi_{2}\left(b_{1}, b_{2}\right)^{1-k}\left\{\left[2-d\left(1+b_{1}\right)\right]\left[d^{2}+k\left(4-d^{2}\right)\right]-4\left(2-d^{2}\right) b_{2}\right\}}{\left[2\left(1+b_{2}\right)-d\left(1+b_{1}\right)\right]\left[2-b_{2}\left(2-d^{2}\right)-d(2+d)\right]}=0 \Leftrightarrow \\
& \Leftrightarrow b_{2}\left(b_{1}\right)=\frac{\left[2-d\left(1+b_{1}\right)\right]\left[d^{2}+k\left(4-d^{2}\right)\right]}{4\left(2-d^{2}\right)}
\end{aligned} .
$$

By using (16) and (17), we definitely obtain the (symmetric) equilibrium value of the bonus bargained by owner and manager within every sales delegated firm, that is:

$$
b_{i}^{S / S}=\frac{d^{2}+k\left(4-d^{2}\right)}{4+d(2-d)+k d(2+d)}>0,
$$

for $0 \leq k<1$ and $-1 \leq d \leq 1$. In addition, it is easy to verify that $\partial b_{i}^{S / S} / \partial k>0$.

From (18), we may easily get equilibrium values of quantity, market price and firm's profit under sales delegation $(\mathrm{S})$, that is:

$$
\begin{aligned}
q_{i}^{S / S} & =\frac{2(1+k)}{4+d(2-d)+k d(2+d)}, \\
p_{i}^{S / S} & =\frac{(1-k)\left(2-d^{2}\right)}{4+d(2-d)+k d(2+d)},
\end{aligned}
$$

and

$$
\Pi_{i}^{S / S}=\frac{2\left(1-k^{2}\right)\left(2-d^{2}\right)}{[4+d(2-d)+k d(2+d)]^{2}} .
$$

Straightforward calculations from (19), (20) and (21) show (for the case of product substitutability ${ }^{12}$ ) that an increase in $k$ causes a monotonic increase (resp. decrease) in the quantity produced by (resp. in the profits of) both delegated firms, whereas it always decreases the market price monotonically. It may also be of interest to ascertain the reasons why the outcome of an increase in $k$ on profits of firm $i$ is negative. This is given by the total derivative of $\Pi_{i}^{S / S}$ with respect to $k$. Then, let

$$
\Pi_{i}^{S / S}=\Pi_{i}^{S / S}\left\{p\left[q_{i}\left(b_{i}(k), b_{j}(k)\right), q_{j}\left(b_{i}(k), b_{j}(k)\right)\right], q_{i}\left(b_{i}(k), b_{j}(k)\right)\right\},
$$

$i=1,2, i \neq j$ be the generic profit function of firm $i$. Its total derivative with respect to $k$ gives:

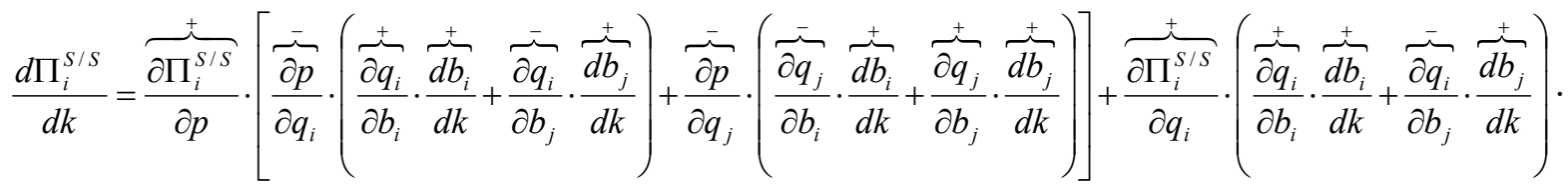

For the case of product substitutability, from this derivative it is clear that the relative bargaining power of the manager affects profits of $i$ th firm through two channels: a direct effect that passes through the quantity produced by that firm, and an indirect effect via the change in market price. With regard to the former effect, an increase in $k$ causes an increase in the incentive parameter for player $i$ and player $j$. The increase in $b_{i}$ (resp. $b_{j}$ ) tends to increase (resp. reduce) the quantity produced by firm $i$. Nevertheless, the net effect of an increase in $k$ on $q_{i}$ is positive, that is the positive effect of the increased incentive parameter of the quantity produced by $i$ th firm dominates the negative effect that passes through the reduced production of the rival. Then, $k$ and $q_{i}$ increase and then $\Pi_{i}^{S / S}$ goes up through this channel. With regard to the latter effect (the indirect negative effect of $k$ on the market price), we have the following. As an increase in $k$ positively affects both $b_{i}$ and $b_{j}$, and the net effect on quantities produced by firm $i$ and firm $j$ is positive, then the

${ }^{12}$ The case of product complementarity is more complicated to be ascertained, as it is apparently ambiguous. Then, we will see later in this article which are the main results of the game when products are complements and the managerial power $(k)$ varies. 
increased production reduces the marginal willingness to pay of consumers, so that the market price goes down and $\Pi_{i}^{S / S}$ declines through this channel. Definitely, the percentage reduction in market price that comes from the increase in $k$ is larger than the percentage increase in total supply, so that profits of both sales delegated firms monotonically reduce when the relative power of managers in the Nash bargaining increases.

\subsection{Mixed behaviour: sales delegation versus profit maximisation}

In this section, we assume that firm 1 hires a manager with a sales delegation contract $\left(b_{1} \neq 0\right)$ and firm 2 is profit maximising ( $\left.b_{2}=0\right)$. Then, at the market stage, firm 1 maximises (5) with respect to $q_{1}$, and firm 2 maximises (4) with respect to $q_{2}$. Therefore, the reaction function of manager of firm 1 and owner of firm 2 are given by:

$$
\frac{\partial u_{1}}{\partial q_{1}}=0 \Leftrightarrow q_{1}\left(q_{2}, b_{1}\right)=\frac{1-d q_{2}+b_{1}}{2}
$$

and

$$
\frac{\partial \Pi_{2}}{\partial q_{2}}=0 \Leftrightarrow q_{2}\left(q_{1}\right)=\frac{1-d q_{1}}{2}
$$

Then, from (22) and (23), we get

$$
\bar{q}_{1}\left(b_{1}\right)=\frac{2\left(1+b_{1}\right)-d}{4-d^{2}}
$$

and

$$
\bar{q}_{2}\left(b_{1}\right)=\frac{2-d\left(1+b_{1}\right)}{4-d^{2}} .
$$

Given that $b_{2}=0$, in the bargaining stage only the owner and the manager of firm 1 are engaged in a Nash bargaining and then maximise (15) with respect to $b_{1}$ by taking into account (24) and (25). Therefore,

$$
\begin{aligned}
& \frac{\partial \mathrm{N}_{1}}{\partial b_{1}}=\frac{u_{1}\left(b_{1}\right)^{k} \Pi_{1}\left(b_{1}\right)^{1-k}\left\{(2-d)\left[d^{2}+k\left(4-d^{2}\right)\right]-4\left(2-d^{2}\right) b_{1}\right\}}{\left[2\left(1+b_{1}\right)-d\right]\left[2-d-b_{1}\left(2-d^{2}\right)\right]}=0 \Leftrightarrow \\
& \Leftrightarrow b_{1}=\frac{(2-d)\left[d^{2}+k\left(4-d^{2}\right)\right]}{4\left(2-d^{2}\right)}
\end{aligned} .
$$

Then, the (asymmetric) equilibrium values of the bonus of player $1(\mathrm{~S})$ and player $2(\mathrm{PM})$ are

$$
b_{1}^{S / P M}=\frac{(2-d)\left[d^{2}+k\left(4-d^{2}\right)\right]}{4\left(2-d^{2}\right)}>0, \quad b_{2}^{S / P M}=0 .
$$

Given (24) equilibrium values of quantity, market price, profit of firm 1 (where the manager is sales delegated) and firm 2 (that does not hire any manager) and manager 1's utility are given by

$$
q_{1}^{S / P M}=\frac{(2-d)(1+k)}{2\left(2-d^{2}\right)}, \quad q_{2}^{S / P M}=\frac{4-d[2(1+k)+d(1-k)]}{4\left(2-d^{2}\right)},
$$

where $4-d[2(1+k)+d(1-k)]>0$ for any $0<k<1$ and $-1 \leq d \leq 1$,

$$
p_{1}^{S / P M}=\frac{(1-k)(2-d)\left(2-d^{2}\right)}{4\left(2-d^{2}\right)}, \quad p_{2}^{S / P M}=\frac{4-d[2(1+k)+d(1-k)]}{4\left(2-d^{2}\right)} .
$$

and

$$
\Pi_{1}^{S / P M}=\frac{\left(1-k^{2}\right)(2-d)^{2}}{8\left(2-d^{2}\right)}, \quad \Pi_{2}^{S / P M}=\frac{\{4-d[2(1+k)+d(1-k)]\}^{2}}{16\left(2-d^{2}\right)^{2}} .
$$


As for the case in which both firms are delegated, we now look at the reasons why the outcome of an increase in $k$ on $\Pi_{1}^{S / P M}$ and $\Pi_{2}^{S / P M}$ is negative for the case of product substitutability. Define the generic profit function of firm $1(\mathrm{~S})$ and firms $2(\mathrm{PM})$ as follows:

$$
\Pi_{1}^{S / P M}=\Pi_{1}^{S / P M}\left\{p\left[q_{1}\left(b_{1}(k)\right), q_{2}\left(b_{1}(k)\right)\right], q_{1}\left(b_{1}(k)\right)\right\},
$$

and

$$
\Pi_{2}^{S / P M}=\Pi_{2}^{S / P M}\left\{p\left[q_{1}\left(b_{1}(k)\right), q_{2}\left(b_{1}(k)\right)\right], q_{2}\left(b_{1}(k)\right)\right\},
$$

Total differentiation of these two functions with respect to $k$ gives:

$$
\frac{d \Pi_{1}^{S / P M}}{d k}=\overbrace{\frac{\partial \Pi_{1}^{S / P M}}{\partial p}}^{+}(\overbrace{\frac{\partial p}{\partial q_{1}}}^{=} \cdot \overbrace{\frac{\partial q_{1}}{\partial b_{1}}}^{+} \cdot \overbrace{\frac{d b_{1}}{d k}}^{+}+\overbrace{\frac{\partial p}{\partial q_{2}}}^{-} \cdot \overbrace{\frac{\partial q_{2}}{\partial b_{1}}}^{-} \cdot \overbrace{\frac{d b_{1}}{d k}}^{+})+\overbrace{\frac{\partial \Pi_{1}^{S / P M}}{\partial q_{1}}}^{+} \cdot \overbrace{\frac{\partial q_{1}}{\partial b_{1}}}^{+} \cdot \overbrace{\frac{d b_{1}}{d k}}^{+},
$$

and

$$
\frac{d \Pi_{2}^{S / P M}}{d k}=\overbrace{\frac{\partial \Pi_{2}^{S / P M}}{\partial p}}^{+} \cdot(\overbrace{\frac{\partial p}{\partial q_{1}}}^{-} \cdot \overbrace{\frac{\partial q_{1}}{\partial b_{1}}}^{+} \overbrace{\frac{d b_{1}}{d k}}^{+}+\overbrace{\frac{\partial p}{\partial q_{2}}}^{-} \cdot \overbrace{\frac{\partial q_{2}}{\partial b_{1}}}^{-} \cdot \overbrace{\frac{d b_{1}}{d k}}^{+})+\overbrace{\frac{\partial \Pi_{2}^{S / P M}}{\partial q_{2}}}^{+} \cdot \overbrace{\frac{\partial q_{2}}{\partial b_{1}}}^{-} \cdot \overbrace{\frac{d b_{1}}{d k}}^{+} .
$$

With regard to the effects on an increase in $k$ on profits of the sales delegated firm, as usual they pass through two distinct channels: a direct effect on quantity and an indirect effect on market price. In fact, a rise in $k$ positively affect the incentive parameter that in turn induces manager hired in firm 1 to increase his how production, so that profits increases through this (direct) channel. In addition, the increase in $k$ that tends to increase $b_{1}$ negatively acts on production of the profit maximising firm 2 . This actually causes an increase in market price and then in profits of firm 1. However, the increase in $b_{1}$ produces a substantial increase in $q_{1}$ and this, in turn, implies a strong reduction in market price that definitely causes a reduction in profits of the delegated firm.

With regard to profit maximising firm 2 , we have that an increase in $k$ induces the same depressing indirect effects on profits (as those detailed above) due to the reduction in the marginal willingness to pay of consumers caused by the increase in $q_{1}$. This negative effect is strengthened by a further negative (direct) force induced by a lower production of firm 2 due to the increase in $b_{1}$. Definitely, profits of the profit maximising firm 2 monotonically reduces as $k$ increases.

\subsection{The contract-bonus stage}

At the contract-bonus stage, players choose the nature of the bonus. To do this, we let firms play a game by comparing profits under sales delegation (S) and profit maximisation (PM). Table 1 shows the payoff matrix that summarises the outcomes of S versus PM. Eqs. (10), (21) and (30) give the payoffs reported in the table.

\begin{tabular}{|c|c|c|}
\hline Firm 1 & $\begin{array}{c}\text { PM } \\
\text { (Cournot) }\end{array}$ & $\begin{array}{c}\text { S } \\
\text { (Cournot) }\end{array}$ \\
\hline $\begin{array}{c}\text { PM } \\
\text { (Cournot) }\end{array}$ & $\Pi_{1}^{P M / P M}, \Pi_{2}^{P M / P M}$ & $\Pi_{1}^{P M / S}, \Pi_{2}^{P M / S}$ \\
\hline $\begin{array}{c}\text { S } \\
\text { (Cournot) }\end{array}$ & $\Pi_{1}^{S / P M}, \Pi_{2}^{S / P M}$ & $\Pi_{1}^{S / S}, \Pi_{2}^{S / S}$ \\
\hline
\end{tabular}

Table 1. Payoff matrix: profits under sales delegation (S) and profit maximisation (PM) with Cournot competition. 
Let $k_{\Delta_{1}}^{C}(d):=\frac{d^{2}}{4-d^{2}} \geq 0$ for any $-1 \leq d \leq 1, k_{\Delta_{2}}^{C}(d):=\left(\frac{-m_{2}}{2}+M\right)^{3}+\left(\frac{-m_{2}}{2}-M\right)^{3} \geq 0$ for any $-1 \leq d \leq 1$ and $k_{\Delta_{3}}^{C}(d):=\frac{-d(4+3 d)}{(2+d)^{2}} \geq 0$ for any $-1 \leq d \leq 0$ be three threshold values of $k$ (under Cournot competition) such that profit differentials $\Delta_{1}^{C}=\Pi_{1}^{S / P M}-\Pi_{1}^{P M / P M}=0, \quad \Delta_{2}^{C}=\Pi_{1}^{P M / S}-\Pi_{1}^{S / S}=0$ and $\Delta_{3}^{C}=\Pi_{1}^{P M / P M}-\Pi_{1}^{S / S}=0$, respectively. The behaviour of $k_{\Delta_{1}}^{C}(d)$ and $k_{\Delta_{3}}^{C}(d)$ is clear as both are positive and smaller than one for any $-1 \leq d \leq 1$, whereas the behaviour of $k_{\Delta_{2}}^{C}(d)$ is much more complicated to be ascertained. Then, before stating the proposition that clarifies whether or not a firm has an incentive to delegate output decisions to managers under Cournot competition, we show that $0 \leq k_{\Delta_{2}}^{C}(d)<1$. First, we note that the zero of $\Delta_{2}$ coincide with the zeros of the polynomial $P(k):=k^{3}+r k^{2}+s k+t=0$, where $r:=\frac{3}{d^{2}\left(4-d^{2}\right)}, s:=\frac{\left(4-3 d^{2}\right)\left(d^{4}-16 d+16\right)}{d^{4}\left(4-d^{2}\right)}$ and $t:=\frac{d^{4}+8 d^{2}-16}{d^{2}\left(4-d^{2}\right)}$.

Let $m_{1}:=s-\frac{r^{3}}{3}$ and $m_{2}:=\frac{2 r^{3}}{27}-\frac{s r}{3}+t$. As the quantity

$$
M:=\frac{m_{1}}{27}+\frac{m_{2}^{2}}{4}=\frac{1024\left(27 d^{4}-40 d^{2}+16\right)\left(2-d^{2}\right)^{6}}{27\left(4-d^{2}\right)^{4} d^{12}},
$$

is positive for any $-1 \leq d \leq 1$, then from Cardano's formula it follows that there exists only one root for $P$ given by $k_{\Delta_{2}}^{C}(d):=\left(\frac{-m_{2}}{2}+M\right)^{3}+\left(\frac{-m_{2}}{2}-M\right)^{3}$. As $P(0) P(1)<0$, it follows that $k_{\Delta_{2}}^{C}(d) \in[0,1)$. Then, the following proposition holds.

Proposition 1. (a) [Cournot - product substitutability $(0 \leq d \leq 1)$ ]. (1) If $0 \leq k<k_{\Delta_{1}}^{C}(d)$ then (S,S) is the unique SPNE of the game and it is Pareto inefficient. In this case, the game falls within the prisoner's dilemma paradigm. (2) If $k_{\Delta_{1}}^{C}(d)<k<k_{\Delta_{2}}^{C}(d)$ then there exist two pure-strategy Nash equilibria, that is (S,S) and (PM,PM), but the former is payoff dominated by the latter. (3) If $k_{\Delta_{2}}^{C}(d)<k<1$ then (PM,PM) is the unique SPNE of the game and it is Pareto efficient.

(b) [Cournot - product complementarity $(-1 \leq d \leq 0)$ ]. (1) If $0 \leq k<k_{\Delta_{1}}^{C}(d)$ then $(\mathrm{S}, \mathrm{S})$ is the unique SPNE of the game and it is Pareto efficient. (2) If $k_{\Delta_{1}}^{C}(d)<k<k_{\Delta_{2}}^{C}(d)$ then there exist two purestrategy Nash equilibria, that is (S,S) and (PM,PM), but the former payoff dominates the latter. (3) If $k_{\Delta_{2}}^{C}(d)<k<k_{\Delta_{3}}^{C}(d)$ then (PM,PM) is the unique SPNE of the game and it is Pareto inefficient. In this case, the game falls within the prisoner's dilemma paradigm. (4) If $k_{\Delta_{3}}^{C}(d)<k<1$ then (PM,PM) is the unique SPNE of the game and it is Pareto efficient.

Proof. Profit differentials are the following:

$$
\begin{gathered}
\Delta_{1}^{C}=\frac{\left[d^{2}-k\left(4-d^{2}\right)\right]\left[d^{2}+k\left(4-d^{2}\right)\right]}{8\left(2-d^{2}\right)(2+d)^{2}}, \\
\Delta_{2}^{C}=\frac{\left[k^{3} d^{4}\left(4-d^{2}\right)+k^{2} 3 d^{6}+k\left(-3 d^{6}+52 d^{4}-112 d^{2}+64\right)+d^{2}\left(d^{4}+8 d^{2}-16\right)\right]\left[d^{2}+k\left(4-d^{2}\right)\right]}{16\left(2-d^{2}\right)^{2}[k d(2+d)+d(2-d)+4]^{2}},
\end{gathered}
$$

and

$$
\Delta_{3}^{C}=\frac{\left[k(2+d)^{2}+d(4+3 d)\right]\left[d^{2}+k\left(4-d^{2}\right)\right]}{(2+d)^{2}[k d(2+d)+d(2-d)+4]^{2}} .
$$

The sign of $\Delta_{1}^{C}, \Delta_{2}^{C}$ and $\Delta_{3}^{C}$ changes depending on the relative position of the degree of bargaining $k$ and the degree of product differentiation $d$. In the case of product substitutability $(0 \leq d \leq 1)$, it 
holds that $\Delta_{3}^{C}>0$ for any $0 \leq k<1$, and (1) if $0 \leq k<k_{\Delta_{1}}^{C}(d)$ then $\Delta_{1}^{C}>0$ and $\Delta_{2}^{C}<0$, (2) if $k_{\Delta_{1}}^{C}(d)<k<k_{\Delta_{2}}^{C}(d)$ then $\Delta_{1}^{C}<0$ and $\Delta_{2}^{C}<0$, (3) if $k_{\Delta_{2}}^{C}(d)<k<1$ then $\Delta_{1}^{C}<0$ and $\Delta_{2}^{C}>0$. Therefore, point (a) follows. In the case of product complementarity $(-1 \leq d \leq 0)$, it holds that (1) if $0 \leq k<k_{\Delta_{1}}^{C}(d)$ then $\Delta_{1}^{C}>0, \Delta_{2}^{C}<0$ and $\Delta_{3}^{C}<0$, (2) if $k_{\Delta_{1}}^{C}(d)<k<k_{\Delta_{2}}^{C}(d)$ then $\Delta_{1}^{C}<0, \Delta_{2}^{C}<0$ and $\Delta_{3}^{C}<0$, (3) if $k_{\Delta_{2}}^{C}(d)<k<k_{\Delta_{3}}^{C}(d)$ then $\Delta_{1}^{C}<0, \Delta_{2}^{C}>0$ and $\Delta_{3}^{C}<0$, (4) if $k_{\Delta_{3}}^{C}(d)<k<1$ then $\Delta_{1}^{C}<0$, $\Delta_{2}^{C}>0$ and $\Delta_{3}^{C}>0$. Therefore, point (b) follows. Q.E.D.

Corollary 1. [Cournot - homogeneous products $(d=1)$ ]. (1) If $0 \leq k<1 / 3$ then there exists a unique SPNE, that is $(\mathrm{S}, \mathrm{S})$, and it is Pareto inefficient, so that a standard prisoner's dilemma emerges. (2) If $1 / 3<k<1$ then there exist two pure-strategy Nash equilibria, that is (S,S) and (PM,PM), and the game becomes a coordination game.

Proof. If $\quad d=1 \quad$ then $\quad \Delta_{1}^{C}=\frac{1}{72}(1+3 k)(1-3 k), \quad \Delta_{2}^{C}=\frac{(1+3 k)\left(3 k^{3}+3 k^{2}+k-7\right)}{16(5+3 k)^{2}}<0 \quad$ and $\Delta_{3}^{C}=\frac{(1+3 k)(7+9 k)}{9(5+3 k)^{2}}>0$. (1) If $0 \leq k<1 / 3$ then $\Delta_{1}^{C}>0, \Delta_{2}^{C}<0$ and $\Delta_{3}^{C}>0$. (2) If $1 / 3<k<1$ then $\Delta_{1}^{C}<0, \Delta_{2}^{C}<0$ and $\Delta_{3}^{C}>0$. Q.E.D.

Proposition 1 shows that there exists a wide range of equilibrium results, depending on the relative size of manager's power as compared with the extent of product differentiation. When products are substitutes, the classical results of Vickers (1985) and of Fershtman and Judd (1987) holds only when the managerial power $k$ is sufficiently small $\left(0 \leq k<k_{\Delta_{1}}^{C}(d)\right)$, i.e. when owners' profits weight relatively more than managers' utility in the Nash product. In fact, in this case, for each player $\mathrm{S}$ strictly dominates PM, so that every firm hires a manager but there exists an incentive for firms to coordinate themselves to play pure profits but no one has a unilateral incentive to deviate from $\mathrm{S}$ (prisoner's dilemma). When $k$ becomes larger $\left(k_{\Delta_{1}}^{C}(d)<k<k_{\Delta_{2}}^{C}(d)\right)$, there exist multiple equilibria in pure strategies. Managers want to maximise their own objective $\left(u_{i}\right)$. In doing this, they tend to increase production when the relative bargaining power increases. Within this range of values of $k$, no dominated strategies do exist because $\Pi_{1}^{S / P M}$ reduces when $k$ increases up to a point at which $\Pi_{1}^{S / P M}$ becomes lower than $\Pi_{1}^{P M / P M}$. The consequence is that there is no more a unilateral incentive for each player to deviate from PM. The economic intuition behind the change in the sign of $\Delta_{1}$ is the following: as $\Pi_{1}^{P M / P M}$ does not depend on $k$, an increase in the relative bargaining power of the manager causes an increase in the incentive parameter $b_{1}$ that, in turn, causes an increase in $q_{1}$. However, the increase in $\Pi_{1}^{S / P M}$ that comes from the increased production of the managerial firm is more than compensated by the reduction in profits due to a reduced marginal willingness to pay of consumers.

As within this range of values of $k$ and $d$ multiple pure-strategy Nash equilibria are supported, the game from a prisoner's dilemma becomes a standard coordination game. Then, it may be useful to adopt a criterion to select equilibria. To this purpose, we introduce mixed strategies and show that a (unique) mixed-strategy Nash equilibrium does actually exist. To proceed further, we consider that a Nash equilibrium in mixed strategies can be obtained by defining probabilities $x_{1}$ and $1-x_{1}$ (resp. $x_{2}$ and $1-x_{2}$ ) that firm 1 (resp. firm 2) plays either S or PM. Therefore, we find that a mixed-strategy Nash equilibrium is given by: 


$$
\begin{aligned}
& x_{1}=x_{2}=x_{*}^{S / P M}=\frac{\Pi_{i}^{S / P M}-\Pi_{i}^{P M / P M}}{\left(\Pi_{i}^{S / P M}-\Pi_{i}^{P M / P M}\right)+\left(\Pi_{i}^{P M / S}-\Pi_{i}^{S / S}\right)}= \\
& =\frac{2\left(2-d^{2}\right)\left[d^{2}-k\left(4-d^{2}\right)\right]\left[d^{2}+k\left(4-d^{2}\right)\right]^{-1}[4+d(2-d)+k d(2+d)]^{2}}{-d\left(4-3 d^{2}\right)(2+d)^{2} k^{2}-2(2+d)\left[d(2+d)\left(d^{2}-8 d+4\right)+16\right] k-d\left(d^{4}-12 d^{3}-24 d^{2}+16 d+32\right)}
\end{aligned}
$$

From (31) it is easy to check that $x_{*}^{S / P M}>0$ only when $k>k_{\Delta_{1}}^{C}(d)$ and it is an increasing function of $k$. This probability vanishes when $k=k_{\Delta_{1}}^{C}(d)$ and approaches 1 when $k \rightarrow k_{\Delta_{2}}^{C}(d)$. This behaviour is in line with the results summarised in Proposition 1, Point (a). In fact, for $k<k_{\Delta_{1}}^{C}(d)$ there exists only one (sub-optimal) Nash equilibrium and the game boils down to the standard prisoner's dilemma found by The VFJS's approach, whereas for $k>k_{\Delta_{2}}^{C}(d)$ (PM,PM) is the Pareto efficient SPNE, thus contrasting the VFJS's result under quantity competition and product substitutability. In this case, no delegation emerges at all and the prisoner's dilemma is solved. The rule that comes from the mixed-strategy Nash equilibrium (31) is therefore the following: each firm will choose to play $\mathrm{S}$ (resp. PM) as a pure strategy if the rival plays $\mathrm{S}$ (resp. PM) with a probability $x>x_{*}^{S / P M}$ (resp. $x<x_{*}^{S / P M}$ ). The higher $k$, the higher the probability of playing PM as a pure strategy. We note that the case of multiple equilibria (that emerges for opportune parametric sets, depicted in region $\mathrm{B}$ of Figure 1 for the case of product substitutability, and in region E of Figure 2 for the case of product complementarity) can be investigated more in detail by resorting to well-known criteria of Pareto-dominance and Risk-dominance for equilibrium selection. ${ }^{13}$ However, for the sake of simplicity, we limit ourselves to point out that whether and how Pareto-dominance appears. This because such a criterion is immediately observable by direct comparison of profits. In fact, when products are substitutes and the parameter configuration supports multiplicity of equilibria in pure strategies, Pareto dominance allows us to conclude that (PM,PM) Pareto dominates (S,S).

When $k$ further increases $\left(k_{\Delta_{2}}^{C}(d)<k<1\right)$, a dramatic change in the structure of the game occurs. In particular, when the weight of manager's utility in the Nash product is sufficiently large, it holds for every that PM strictly dominates S. In fact, the increase in $k$ produces an incentive for both firms to deviate from $\mathrm{S}$ and play PM irrespective of what the other player does, that is both $\Pi_{1}^{P M / S}$ and $\Pi_{1}^{S / S}$ reduce when $k$ goes up, but the percentage reduction in $\Pi_{1}^{S / S}$ is larger than the percentage reduction in $\Pi_{1}^{P M / S}$, so that the Nash equilibrium (PM,PM) and it is Pareto efficient.

Figure 1 summarises the results stated in Proposition 1, Point (a) showing three areas in which the sign of profit differentials change in parameter space $(k, d)$ when product are substitutes. The figure clearly shows the key role played by both the manager's bargaining power and the extent of product differentiation in choosing whether to delegate or not. In fact, when products from homogeneous tend to become heterogeneous, the degree of competition reduces, so that equilibrium values of quantities and profits increase. Therefore, ceteris paribus, the utility of every manager tends to become larger and the required manager's effort in the bargaining process with the owner to choose executive remuneration can actually be smaller to capture the benefits of product differentiation. Therefore, the lower $d$, the lower the value of $k$ that leads to area $\mathrm{C}$ of Figure 1, where the unique SPNE of the game is (PM,PM) and it is Pareto efficient.

When products are complements, the classical VFJS's result holds only when the managerial power is sufficiently small $\left(0 \leq k<k_{\Delta_{1}}^{C}(d)\right)$, as for the case of product substitutability. There exists a strictly dominated strategy (S strictly dominates PM). Definitely, in this case firm hires a manager and $(\mathrm{S}, \mathrm{S})$ is Pareto efficient, as $\Delta_{1}^{C}>0$ so that each player plays $\mathrm{S}$ no matter what the rival does. An increase in $\left(k_{\Delta_{1}}^{C}(d)<k<k_{\Delta_{2}}^{C}(d)\right)$, changes the paradigm of the game, as $\Delta_{1}^{C}$ becomes negative and no dominated strategies exist anymore. There are multiple equilibria in pure strategies and the game

\footnotetext{
${ }^{13}$ A Nash equilibrium is said to be Payoff-dominant if it is Pareto superior to all other Nash equilibria in the game and Risk-dominant if it is less risky.
} 
takes the form of a coordination game. A unique mixed-strategy Nash equilibrium also exists, as in the case of product substitutability. The rule that comes from (31) in when products are complements is the same as before. Each firm will choose to play S (resp. PM) as a pure strategy if the rival plays $\mathrm{S}$ (resp. PM) with a probability $x>x_{*}^{S / P M}$ (resp. $x<x_{*}^{S / P M}$ ). The Pareto dominance criterion now suggests that both players should play $\mathrm{S}$ rather than PM, as $(\mathrm{S}, \mathrm{S})$ Pareto dominates (PM,PM).

When $k_{\Delta_{2}}^{C}(d)<k<k_{\Delta_{3}}^{C}(d)$, we observe a change in the sign of $\Delta_{2}$ that becomes positive. In fact, the increase in $k$ causes an increase in both $\Pi_{1}^{P M / S}$ and $\Pi_{1}^{S / S}$. However, the percentage increase in $\Pi_{1}^{P M / S}$ is larger than the percentage increase $\Pi_{1}^{S / S}$, so that $\mathrm{S}$ is strictly dominated by PM. As $\Delta_{3}$ does not change its sign, the Nash equilibrium (PM,PM) is Pareto inefficient. The opposite prisoner's dilemma of VFJS is found. In fact, firms would obtain a higher profitability by coordinating towards $\mathrm{S}$, but each player does not have a unilateral incentive to deviate from PM.

Finally, when $k$ continues to increase and falls within the range $k_{\Delta_{3}}^{C}(d)<k<1, \Pi_{1}^{S / S}$ increases and then $\Delta_{3}$ becomes positive. Therefore, (PM,PM) is the unique SPNE of the game and it is Pareto efficient. Then, no delegation emerges at all and the prisoner's dilemma is solved also in the case of product complementarity. Figure 2 summarises the results stated in Proposition 1, Point $b$, showing four areas in which the sign of profit differentials change in $(k, d)$ plane when product are complements. When the extent of product complementarity increases, managers are required to increase their effort in the bargaining process in order to obtain a higher pay. This because when products tend to become more complements, profits increase and managers should put higher effort to share the benefit of higher profits with the rival.

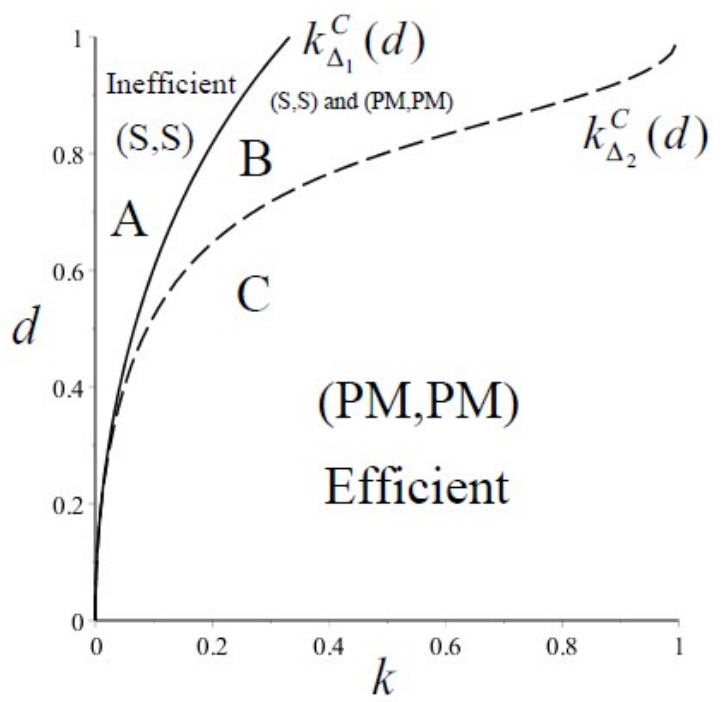

Figure 1. The bargaining-sales-delegation game with quantity-setting firms. Profit differentials in $(k, d)$ space when products are substitutes $(d>0)$.

Let us further comment Figure 1. In region A the following inequalities hold true: $\Delta_{1}^{C}>0, \Delta_{2}^{C}<0$ and $\Delta_{3}^{C}>0$. As a consequence, $(\mathrm{S}, \mathrm{S})$ is the (inefficient) SPNE. This result is in line with the "classical" VFJS's result. By contrast, in region B $\Delta_{1}^{C}<0, \Delta_{2}^{C}<0$ and $\Delta_{3}^{C}>0$ hold. Therefore, $(\mathrm{S}, \mathrm{S})$ and $(\mathrm{PM}, \mathrm{PM})$ are the two pure-strategy Nash equilibria of the game. The Pareto dominance criterion is useful to conclude that (PM,PM) Pareto dominates (S,S). In area $\mathrm{C}$ the set of inequalities $\Delta_{1}^{C}<0, \Delta_{2}^{C}>0$ and $\Delta_{3}^{C}>0$ holds true. This implies that (PM,PM) is the (efficient) SPNE of the 
game. The result emerging in area C steeply contrasts the "classical" VFJS's result. No sales delegation emerges at all and the prisoner's dilemma is solved.

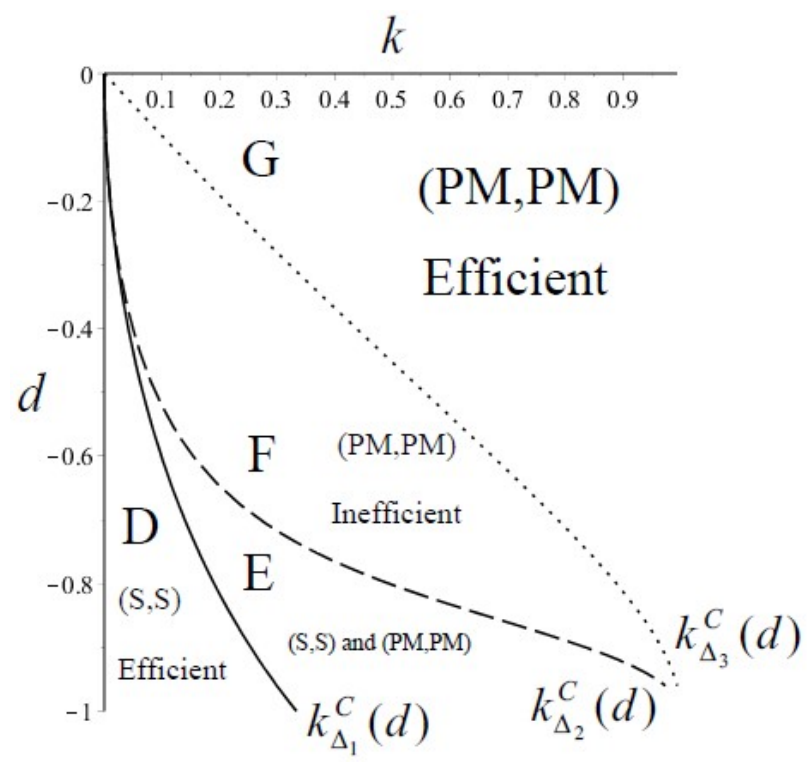

Figure 2. The bargaining-sales-delegation game with quantity-setting firms. Profit differentials in $(k, d)$ space when products are complements $(d<0)$.

Figure 2 allows us to observe for the case of product complementarity that in area D the set of inequalities $\Delta_{1}^{C}>0, \Delta_{2}^{C}<0$ and $\Delta_{3}^{C}<0$ holds true. This implies that (S,S) is the (efficient) SPNE. This area resembles the "classical" VFJS's result under product complementarity. By contrast, in area $\mathrm{E}$ it holds that $\Delta_{1}^{C}<0, \Delta_{2}^{C}<0$ and $\Delta_{3}^{C}<0$. Therefore, (S,S) and (PM,PM) are the two purestrategy Nash equilibria of the game, and the Pareto dominance criterion allows us to select $(\mathrm{S}, \mathrm{S})$ as the Pareto dominant equilibrium. In area $\mathrm{F}$ it holds that $\Delta_{1}^{C}<0, \Delta_{2}^{C}>0$ and $\Delta_{3}^{C}<0$. These inequalities reveal that (PM,PM) is the (inefficient) SPNE. Therefore, the result in the area $\mathrm{F}$ is of importance as it is actually the opposite of VFJS's result. Indeed, firms would have an incentive to delegate (profits would be higher under S), but they do not unilaterally. In this sense, the prisoner's dilemma that holds in the Cournot game with substitutability of products in VFJS (and that it does not exists in VFJS with complements goods) re-emerges under product complementarity but with the opposite equilibrium choice with respect to the VFJS's result. Finally, in area G the inequalities $\Delta_{1}^{C}<0, \Delta_{2}^{C}>0$ and $\Delta_{3}^{C}>0$ hold true, implying that (PM,PM) is the (efficient) SPNE. The equilibrium emerging in area $\mathrm{G}$ contrasts the main finding of VFJS. In fact, no sales delegation emerges at all and the prisoner's dilemma is solved.

\section{The bargaining-sales-delegation game with price-setting firms}

In this section, we present an analysis of a three-stage delegation game with price competition where the nature of the bonus is endogenous. From the inverse demand (2) and the corresponding counterpart of product of variety $j$, we obtain the direct demand of product $i$ as a function of prices of product of both varieties, that is:

$$
q_{i}=\frac{1-p_{i}-d\left(1-p_{j}\right)}{1-d^{2}},
$$


where $-1 \leq d<1$. By accounting for all the steps detailed in Section 2 with regard to pure profit maximisation, sales delegation and mixed behaviours, below we summarise equilibrium values of prices, quantities and profits of a bargaining-sales-delegation game with price competing players.

\subsection{Pure profit maximisation (PM)}

In the standard case of profit-maximising firms, owner of firm $i$ maximise profits with respect to $p_{i}$ given direct demand (32). Then, we easily find the following:

$$
\begin{gathered}
p_{i}^{P M / P M}=\frac{1-d}{2-d}, \\
q_{i}^{P M / P M}=\frac{1}{(2-d)(1+d)},
\end{gathered}
$$

and

$$
\Pi_{i}^{P M / P M}=\frac{(1-d)^{2}}{(2-d)^{2}\left(1-d^{2}\right)} .
$$

When the extent of product differentiation increases ( $d$ reduces), the price increases, the quantity increases if $d<1 / 2$ and profits increase.

\subsection{Sales delegation (S)}

Under sales delegation contracts, the manager of $i$ th firm chooses the price of variety $i$ by maximising his utility at the market stage given (32), whereas at the bargaining stage both the owner and manager choose executive remuneration by taking into account the optimal values of prices of both varieties as functions of $b_{i}$ and $b_{j}$. The results are the following:

$$
\begin{gathered}
b_{i}^{S / S}=\frac{(1-d)\left[k\left(4-d^{2}\right)-d^{2}\right]}{4-d(2+d)+k d(2-d)}, \\
p_{i}^{S / S}=\frac{2(1-d)(1-k)}{4-d(2+d)+k d(2-d)}, \\
q_{i}^{S / S}=\frac{(1+k)\left(2-d^{2}\right)}{(1+d)[4-d(2+d)+k d(2-d)]},
\end{gathered}
$$

and

$$
\Pi_{i}^{S / S}=\frac{2\left(1-k^{2}\right)(1-d)\left(2-d^{2}\right)}{(1+d)[4-d(2+d)+k d(2-d)]^{2}},
$$

where $4-d(2+d)+k d(2-d)>0$ for any $0 \leq k<1$ and $-1 \leq d<1$. From (36), the following proposition holds.

Proposition 2. In a bargaining-sales-delegation game with price competition, there exist incentives (resp. disincentives) for managers if $k>k_{\Delta_{1}}^{C}(d)$ (resp. $k<k_{\Delta_{1}}^{C}(d)$ ) for any $-1 \leq d<1$. If executive pay is chosen only by owners by profit maximisation $(k=0)$, they always provide disincentives to managers.

Proof. The proof is obvious by a simple inspection of (36). In fact, $b_{i}^{S / S}>0$ (resp. $b_{i}^{S / S}<0$ ) if and only if $k>k_{\Delta_{1}}^{C}(d)\left(\right.$ resp. $\left.0 \leq k<k_{\Delta_{1}}^{C}(d)\right)$, where we recall that $k_{\Delta_{1}}^{C}(d):=d^{2} /\left(4-d^{2}\right)$. Q.E.D.

If the relative weight of the utility of the manager is relatively small in the bargaining process to choose the size and direction of executive remuneration, the maximisation of the Nash product in 
(15) requires a disincentive to managers. This holds irrespective of whether products are substitutes or complements. In fact, owners' profit weights relatively more than manager's utility when $k$ is small. However, an exogenous increase in it changes the direction of executive pay, as managers' pressure tends to dominate owners' interest in the Nash bargaining, thus providing incentives rather than disincentives to management.

\subsection{Mixed behaviour: sales delegation versus profit maximisation}

If firm 1 is sales delegated and firm 2 is profit maximising, equilibrium results are summarised as follows:

$$
\begin{gathered}
b_{1}^{S / P M}=\frac{(1-d)(2+d)\left[k\left(4-d^{2}\right)-d^{2}\right]}{4\left(2-d^{2}\right)}, \quad b_{2}^{S / P M}=0 \\
p_{1}^{S / P M}=\frac{(1-k)(1-d)(2+d)}{2\left(2-d^{2}\right)}, \quad p_{2}^{S / P M}=\frac{(1-d)[4+d(2-d)-k d(2+d)]}{4\left(2-d^{2}\right)} \\
q_{1}^{S / P M}=\frac{(2+d)(1+k)}{4(1+d)}, \quad q_{2}^{S / P M}=\frac{4+d(2-d)-k d(2+d)}{4(1+d)\left(2-d^{2}\right)}
\end{gathered}
$$

and

$$
\Pi_{1}^{S / P M}=\frac{\left(1-k^{2}\right)(1-d)(2+d)^{2}}{8(1+d)\left(2-d^{2}\right)}, \quad \Pi_{2}^{S / P M}=\frac{(1-d)[4+d(2-d)-k d(2+d)]^{2}}{16(1+d)\left(2-d^{2}\right)^{2}} .
$$

From (40), the following proposition holds.

Proposition 3. In a bargaining-sales-delegation game under price competition when only firm 1 is sales-delegated, there exist incentives (resp. disincentives) for managers if $k>k_{\Delta_{1}}^{C}(d)$ (resp. $\left.k<k_{\Delta_{1}}^{C}(d)\right)$ for any $-1 \leq d<1$. If executive pay of manager 1 is chosen only by his owner by profit maximisation $(k=0)$, he always provides disincentives to him.

Proof. The proof is obvious by a simple inspection of (40). In fact, $b_{1}^{S / P M}>0$ (resp. $b_{1}^{S / P M}<0$ ) if and only if $k>k_{\Delta_{1}}^{C}(d)\left(\right.$ resp. $\left.0 \leq k<k_{\Delta_{1}}^{C}(d)\right)$, where we recall that $k_{\Delta_{1}}^{C}(d):=d^{2} /\left(4-d^{2}\right)$. Q.E.D.

\subsection{The contract-bonus stage}

We summarise the available choices of firm 1 and firm 2 to choose the nature of the bonus in Table 2, which shows the outcomes of S versus PM. Eqs. (35), (39) and (43) give the payoffs reported in the table.

\begin{tabular}{|c|c|c|}
\hline Firm 2 & $\begin{array}{c}\text { PM } \\
\text { (Bertrand) }\end{array}$ & $\begin{array}{c}\text { S } \\
\text { (Bertrand) }\end{array}$ \\
\hline $\begin{array}{c}\text { PM } \\
\text { (Bertrand) }\end{array}$ & $\Pi_{1}^{P M / P M}, \Pi_{2}^{P M / P M}$ & $\Pi_{1}^{P M / S}, \Pi_{2}^{P M / S}$ \\
\hline $\begin{array}{c}\text { S } \\
\text { (Bertrand) }\end{array}$ & $\Pi_{1}^{S / P M}, \Pi_{2}^{S / P M}$ & $\Pi_{1}^{S / S}, \Pi_{2}^{S / S}$ \\
\hline
\end{tabular}

Table 2. Payoff matrix: profits under sales delegation (S) and profit maximisation (PM) with Bertrand competition.

Let $k_{\Delta}^{B}(d):=\frac{d^{2}}{4-d^{2}}=k_{\Delta_{1}}^{C}(d) \geq 0$ for any $-1 \leq d<1$ be a threshold value of $k$ (under Bertrand competition) such that profit differentials $\Delta_{1}^{B}=\Pi_{1}^{S / P M}-\Pi_{1}^{P M / P M}=0, \quad \Delta_{2}^{B}=\Pi_{1}^{P M / S}-\Pi_{1}^{S / S}=0$ and 
$\Delta_{3}^{B}=\Pi_{1}^{P M / P M}-\Pi_{1}^{S / S}=0$. Let $k_{\Delta_{3}}^{B}(d):=\frac{-d(4-3 d)}{(2-d)^{2}}>k_{\Delta}^{B}(d) \geq 0$ for any $-1 \leq d \leq 0$ be a threshold value of $k$ such that $\Delta_{3}^{B}=\Pi_{1}^{P M / P M}-\Pi_{1}^{S / S}=0$. Then, the following proposition holds.

Proposition 4. (a) [Bertrand - product substitutability $(0 \leq d<1)$ ]. (1) If $0 \leq k<k_{\Delta}^{B}(d)$ then (S,S) is the unique SPNE of the game and it is Pareto efficient. There exist incentives for managers. (2) If $k_{\Delta}^{B}(d)<k<1$ then (PM,PM) is the unique SPNE of the game and it is Pareto efficient.

(b) [Bertrand - product complementarity $(-1 \leq d \leq 0)$ ]. (1) If $0 \leq k<k_{\Delta}^{B}(d)$ then $(\mathrm{S}, \mathrm{S})$ is the unique SPNE of the game and it is Pareto inefficient. In this case, the game falls within the prisoner's dilemma paradigm, and there exist incentives for managers. (2) If $k_{\Delta}^{B}(d)<k<k_{\Delta_{3}}^{B}(d)$ then (PM,PM) is the unique SPNE of the game and it is Pareto inefficient. In this case, the game falls within the prisoner's dilemma paradigm. (3) If $k_{\Delta_{3}}^{B}(d)<k<1$ then (PM,PM) is the unique SPNE of the game and it is Pareto efficient.

Proof. Profit differentials are the following:

$$
\begin{gathered}
\Delta_{1}^{B}=\frac{(1-d)\left[d^{2}-k\left(4-d^{2}\right)\right]\left[d^{2}+k\left(4-d^{2}\right)\right]}{8\left(2-d^{2}\right)(2-d)^{2}(1+d)}, \\
\Delta_{2}^{B}=\frac{(1-d)\left[d^{2}-k\left(4-d^{2}\right)\right]\left[k^{3} d^{4}\left(d^{2}-4\right)+k^{2} 3 d^{6}+k\left(3 d^{6}-52 d^{4}+112 d^{2}-64\right)+d^{2}\left(d^{4}+8 d^{2}-16\right)\right]}{16(1+d)\left(2-d^{2}\right)^{2}[k d(d-2)+d(2+d)-4]^{2}},
\end{gathered}
$$

and

$$
\Delta_{3}^{B}=\frac{-(1-d)\left[k(2-d)^{2}+d(4-3 d)\right]\left[d^{2}-k\left(4-d^{2}\right)\right]}{(1+d)(2-d)^{2}[k d(d-2)+d(2+d)-4]^{2}} .
$$

The sign of $\Delta_{1}^{B}, \Delta_{2}^{B}$ and $\Delta_{3}^{B}$ changes depending on the relative position of the degree of bargaining $k$ and the degree of product differentiation $d$. In the case of product substitutability $(0 \leq d<1)$, it holds that (1) if $0 \leq k<k_{\Delta}^{B}(d)$ then $\Delta_{1}^{B}>0, \Delta_{2}^{B}<0$ and $\Delta_{3}^{B}<0$, (2) if $k_{\Delta}^{B}(d)<k<1$ then $\Delta_{1}^{B}<0, \Delta_{2}^{B}>0$ and $\Delta_{3}^{B}>0$. Therefore, point (a) follows. In the case of product complementarity $(-1 \leq d \leq 0)$, it holds that (1) if $0 \leq k<k_{\Delta}^{B}(d)$ then $\Delta_{1}^{B}>0, \Delta_{2}^{B}<0$ and $\Delta_{3}^{B}>0$, (2) if $k_{\Delta}^{B}(d)<k<k_{\Delta_{3}}^{B}(d)$ then $\Delta_{1}^{B}<0$, $\Delta_{2}^{B}>0$ and $\Delta_{3}^{B}<0$, (3) if $k_{\Delta_{3}}^{B}(d)<k<1$ then $\Delta_{1}^{B}<0, \Delta_{2}^{B}>0$ and $\Delta_{3}^{B}>0$. Therefore, point (b) follows.

\section{Q.E.D.}

Incentives for managers exist only when $k$ is sufficiently high (i.e., $k>k_{\Delta}^{B}(d)$ ). However, they will never be provided as when $k>k_{\Delta}^{B}(d)$ the Nash equilibrium is (PM,PM). Indeed, if managers' pressure in determining their pay is too large, firms find it convenient to do not design a sales delegation contract and then they will behave as profit maximisers. Figures 3 and 4 illustrate the content of Proposition 4 for the cases of product substitutability and product complementarity, respectively. 


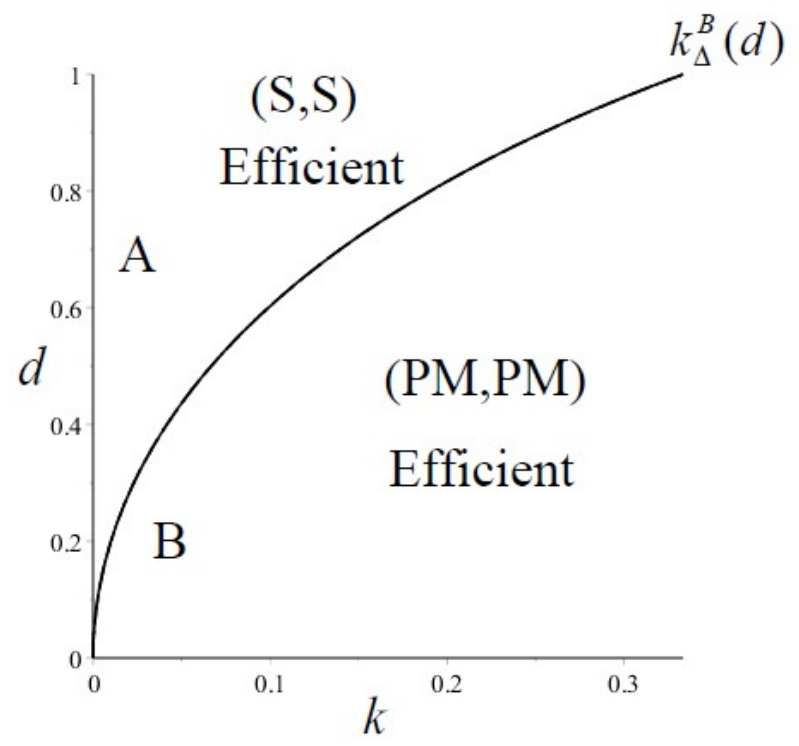

Figure 3. The bargaining-sales-delegation game with price-setting firms. Products are substitutes $(d>0)$. Profit differentials in $(k, d)$ space.

Figure 3. In region $A$ it holds that $\Delta_{1}^{B}>0, \Delta_{2}^{B}<0$ and $\Delta_{3}^{B}<0$. This implies that $(\mathrm{S}, \mathrm{S})$ is the (efficient) SPNE. Notice that for the parameter configuration that leads to area A it emerges for price competition and substitute goods the same result that VFJS find for quantity competition and complement goods. In area $\mathrm{B}$ it holds that $\Delta_{1}^{B}<0, \Delta_{2}^{B}>0$ and $\Delta_{3}^{B}>0$, so that (PM,PM) is the (efficient) SPNE. The result related to area B sharply contrasts VFJS's main findings under price competition and product substitutability. No sales delegation emerges and the prisoner's dilemma is solved with price competition and substitutability of products.

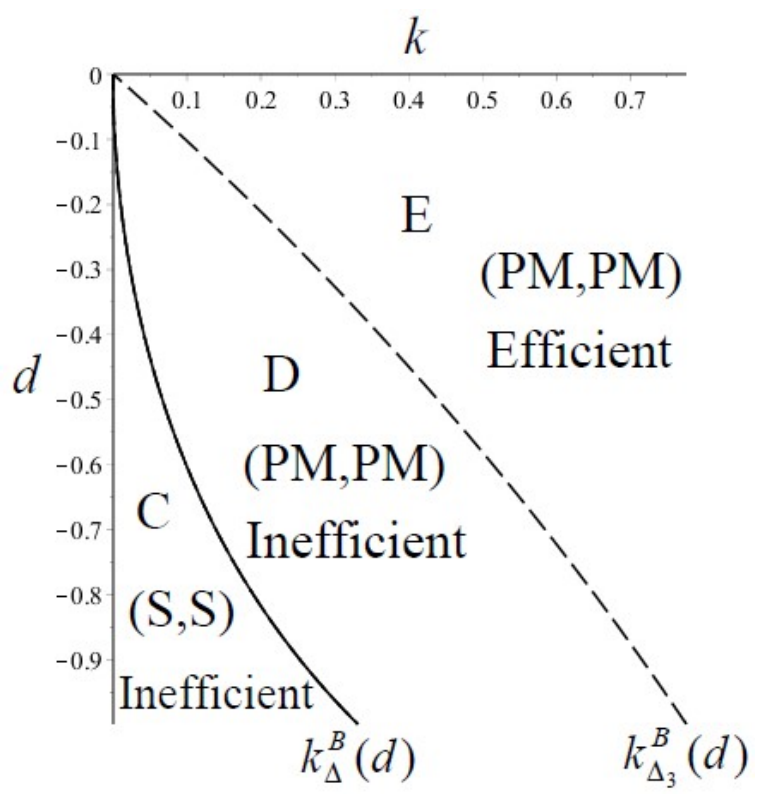

Figure 4. The bargaining-sales-delegation game with price-setting firms. Products are complements $(d<0)$. Profit differentials in $(k, d)$ space. 
Figure 4. In area $\mathrm{C}$ it is true that $\Delta_{1}^{B}>0, \Delta_{2}^{B}<0$ and $\Delta_{3}^{B}>0$. Therefore (S,S) is the (inefficient) SPNE. In this area, it emerges for complements goods the same result that VFJS find for substitute goods. In area D profit differentials are $\Delta_{1}^{B}<0, \Delta_{2}^{B}>0$ and $\Delta_{3}^{B}<0$. Then, it follows that (PM,PM) is the (inefficient) SPNE. A combination of $k$ and $d$ leading in this region causes the appearance of a prisoner's dilemma in price competition at all "reversed" with respect to the one existing in the traditional VFJS's result. Firms would have an incentive to delegate (profits would be higher under $\mathrm{S})$, but they do not unilaterally. In area $\mathrm{E}$ we observe that $\Delta_{1}^{B}<0, \Delta_{2}^{B}>0$ and $\Delta_{3}^{B}>0$. This implies that (PM,PM) is the (efficient) SPNE. The traditional VFJS's result under price competition and product complementarity is at all revised. No sales delegation emerges and the prisoner's dilemma is solved.

\section{Discussion of the main results}

This section provides a discussion about the economic intuitions of the main results of the article. Specifically, it would be instructive to discuss the reasons why an owner who competes according to the Bertrand rules does not find it profitable (unilaterally) to hire a manager whose bargaining power (as measured by $k$ ) is sufficiently large. In the absence of any bargaining process, the owner chooses unilaterally a negative bonus in the manager pay (i.e., the owner disincentives the manager on the quantity produced), so hiring him implies a lower production with higher prices and larger profits. However, when the bargaining power of the manager is positive, and it is large enough to allow him obtaining a positive bonus (incentive) in his pay, then a firm's owner finds it profitable to do not hire a manager (or, alternatively, he hires a manager and lets him behave as a profit maximiser). This because in that case, high values of $k$, sales delegation would imply larger quantities and lower prices and profits. The negative effect on profits of a large value of $k$ is such that at the same threshold allowing the manager to get an incentive, the owner finds it convenient to do not hire the manager unilaterally or, alternatively, if a manager had already been employed, firing him or let him behave as if it were the owner (profit maximiser). In particular, if products are differentiated enough (small values of $d$ ) and hence competition between firms is low and profits are high, even a very small effort puts by the manager in the bargaining over $b_{i}$ with the owner allows the former to extract as much revenue as possible from the lack of competition. Then it will be less and less profitable to hire a manager in a firm as long as products tend to be perceived as little substitutable between them. On the contrary, if products are homogeneous enough (large values of $d$ ) for consumers, the opposite holds, i.e. competition between firms is high, profits tend to zero and the manager is unable to negotiate a positive value of the bonus in his pay. Therefore, hiring a manager is never harmful to the owner in that case.

Under Cournot competition, instead, it is never convenient to do not hire a manager in a firm even for large values of his bargaining power. In fact, an important difference between Bertrand and Cournot competition models is that in this last case we may observe coexistence of Nash equilibria, that is $((\mathrm{S}, \mathrm{S})$ and $(\mathrm{PM}, \mathrm{PM}))$, when products are sufficiently substitutes between each other and the bargaining power of the manager is sufficiently high. We now discuss the reasons why under Cournot competition (in contrast with the Bertrand case) it is not profitable to deviate from a situation in which both firms delegate towards a unilateral profit-maximising behaviour. The behaviour of Cournot and Bertrand players depends on the interplay between the price and quantity effects induced by the manager's power in determining the different profitability of the same strategic situation, as clarified below.

Let us begin with the model of Cournot rivalry. A first observation is that in the case of mixed behaviour, an increase in $k$ in the managerial firm reduces both price and quantity of the profit

maximising firm, that is $\partial p_{i}^{P M / S} / \partial k<0$ and $\partial q_{i}^{P M / S} / \partial k<0$. In contrast, in the case in which both firms are sales delegated an increase in $k$ reduces the price and increases the quantity produced in 
both managerial firms, that is $\partial p_{i}^{S / S} / \partial k<0$ and $\partial q_{i}^{S / S} / \partial k>0$. However, the price of the firm that deviates from sales delegation to profit maximisation reduces less than when both firms are delegated, that is $\left|\partial p_{i}^{P M / S} / \partial k\right|<\left|\partial p_{i}^{S / S} / \partial k\right|$. On the other hand, with a larger value of $k$ the increase in the quantity when both firms are delegated is smaller than the reduction in the quantity produced by the deviating firm, that is $\left|\partial q_{i}^{P M / S} / \partial k\right|>\left|\partial q_{i}^{S / S} / \partial k\right|$. Therefore, it is natural to wonder whether a firm should continue to be sales delegated or become a profit maximiser when $k$ increases. However, given the counterbalancing effects on profits of a rise in $k$ (that pass through changes in prices and quantities), nothing can be said about the convenience to deviate unilaterally from sales delegation to profit maximisation at this stage. This deviation crucially depends on whether the percentage reduction in price and the percentage increase in the quantity differential of the rival firm under $\mathrm{PM} / \mathrm{S}$ reduces or increases profits in comparison with the $\mathrm{S} / \mathrm{S}$ case, where an increase in $k$ causes a larger reduction in price with respect to the extent of the change in the quantity differential. We now provide a simple numerical example to understand the interplay between the forces above mentioned at work. By assuming perfect substitutability $(d=1)$, it is easy to see that when $k=0$ (for which $\pi_{i}^{P M / S}<\pi_{i}^{S / S}$ and it would not be profitable to deviate) we have the following equilibrium prices and quantities: $p_{i}^{P M / S}=0.25, \quad p_{i}^{S / S}=0.20, \quad q_{i}^{P M / S}=0.25$ and $q_{i}^{S / S}=0.40$. Then, the ratios between prices and quantities in the different strategic situations are $\frac{p_{i}^{P M / S}}{p_{i}^{S / S}}=0.5$ and $\frac{q_{i}^{P M / S}}{q_{i}^{S / S}}=0.625$. When $k \rightarrow 1$ we have that $\frac{p_{i}^{P M / S}}{p_{i}^{S / S}} \rightarrow 2$ and $\frac{q_{i}^{P M / S}}{q_{i}^{S / S}}=0$. As a consequence, in the case of unilateral deviation, the relative advantage in terms of price is more than offset by the disadvantage in terms of quantity when $k$ increases. Then, it will result always unprofitable for one firm to unilaterally deviate for any $k$.

In the case of Bertrand rivalry, at a first general sight we observe the same counterbalancing effects on profits of an increase in $k$ in the different strategic situations analysed under Cournot competition. By using the same line of reasoning, we may disentangle the interplay between the price effect and the quantity effect. Under price competition, the effect of a deviation on profits becomes positive. This is an important difference with the quantity competition model analysed previously. By assuming a sufficiently high degree of product substitutability $(d=0.9)$, it is easy to see that when $k=0$ (for which $\pi_{i}^{P M / S}<\pi_{i}^{S / S}$ and it would not be profitable to deviate) we get: $p_{i}^{P M / S}=0.105, p_{i}^{S / S}=0.144, q_{i}^{P M / S}=0.55$ and $q_{i}^{S / S}=0.45$. Therefore, the ratios between prices and quantities in the different strategic situations are the following: $\frac{p_{i}^{P M / S}}{p_{i}^{S / S}}=0.73$ and $\frac{q_{i}^{P M / S}}{q_{i}^{S / S}}=1.22$. When $k \rightarrow 1$ these ratios tend to become $\frac{p_{i}^{P M / S}}{p_{i}^{S / S}} \rightarrow+\infty$ and $\frac{q_{i}^{P M / S}}{q_{i}^{S / S}}=0.5$. As a consequence, it is easy to see that, when $k$ increases, the relative disadvantage in terms of output reduction in the case of unilateral deviation is more than offset by the relative advantage associated with the increase in price. Therefore, it will result profitable for one firm to unilaterally deviate for a sufficiently large value of $k$.

We now use this line of reasoning to inquire about the reasons why in both Cournot and Bertrand duopolies there exists the same threshold of $k$ with respect to which a firm wants to deviate from $\mathrm{S}$ to PM. Let us begin with the Cournot case by considering $d=0.9$ and $k=0$. In the absence of any bargaining, $\pi_{i}^{S / P M}>\pi_{i}^{P M / P M}$ so that it is not profitable to deviate from $\mathrm{S}$. Then, we get $p_{i}^{S / P M}=0.127, p_{i}^{P M / P M}=0.344, q_{i}^{S / P M}=0.462$ and $q_{i}^{P M / P M}=0.344$. With these values of prices 
and quantities, we obtain $\frac{p_{i}^{S / P M}}{p_{i}^{P M / P M}}=0.797 \quad$ and $\quad \frac{q_{i}^{S / P M}}{q_{i}^{P M / P M}}=1.34$. By setting now $k=k_{\Delta_{1}}^{C}(d)=k_{\Delta}^{B}(d)=0.2539$ we find that $\frac{p_{i}^{S / P M}}{p_{i}^{P M / P M}}=1.68$ and $\frac{q_{i}^{S / P M}}{q_{i}^{P M / P M}}=0.595$. It is easy to see that the ratios between the equilibrium values of prices more than doubles, whereas the ratio between the equilibrium values of quantities more than halves. Instead, by considering the Bertrand case when $d=0.9$ and $k=0$ we find that the equilibrium values of prices and quantities in the two different strategic situations are the following: $p_{i}^{S / P M}=0.121, p_{i}^{P M / P M}=0.09, q_{i}^{S / P M}=0.381$ and $q_{i}^{P M / P M}=0.478$. Therefore, $\frac{p_{i}^{S / P M}}{p_{i}^{P M / P M}}=1.34$ and $\frac{q_{i}^{S / P M}}{q_{i}^{P M / P M}}=0.797$, which is exactly the opposite situation with respect to the Cournot model, whereas when $k=0.2539$ these ratios become $\frac{p_{i}^{S / P M}}{p_{i}^{P M / P M}}=1$ and $\frac{q_{i}^{S / P M}}{q_{i}^{P M / P M}}=1$. As expected, prices now reduce and quantities increase (in both case the percentage variation is almost 25 per cent). As can easily be seen by looking at this numerical examples, the percentage variations in prices and quantities in the profit formulae in both Cournot and Bertrand settings when $k$ varies lead, although through the working of different forces that pass through different channels, to the same threshold that marks the start for a unilateral deviation from being a sales-delegated firm.

\section{Concluding remarks}

This article revisits the "classical" managerial (sales) delegation literature led by Vickers (1985), Fershtman and Judd (1987) and Sklivas (1987) (VFJS throughout the article). According to VFJS's view, there exists a three-stage endogenous game (solved by adopting the standard backward logic), detailed as follows. At stage 1 (the contract-bonus stage), firms strategically choose the nature of the bonus (pure profits or sales delegation). At stage 2 (the contract stage), owners design executive remuneration by maximising profits (that is, each firm's owner offers a "take-it-or-leave-it" incentive contract to his manager). At stage 3 (the market stage), managers strategically choose either the quantity (in the case of quantity-setting behaviour) or the price (in the case of pricesetting behaviour). The outcome of this game in a Cournot duopoly with homogeneous product is the following: each firm hires a manager and delegates output decisions to him; although both players have an incentive to be profit maximisers, no one has a unilateral incentive to deviate from sales delegation (prisoner's dilemma).

Different from VFJS, we assume that as stage 2 (to which we refer to as the bargaining stage) owners or boards of directors in large public companies (attempting to get the maximum profits or the best possible deal for shareholders) and managers (aiming to get the most favourable treatment for themselves) are engaged in designing together executive remuneration. In order to do that, they maximise a Nash product that weights firm's profits and manager's utility, as in van Witteloostuijn et al. (2007). This hypothesis is made to better capture the actual behaviour of ownership and top management in large corporations. Our bargaining mechanism is in line with both the view that several decisions in a firm are taken because of a bargaining process and the dominant paradigm of financial economists (i.e., the "arm's-length bargaining" approach). The interaction between these two bargaining parties over executive remuneration dramatically changes the standard view that firms have an incentive to hire a manager and delegate output decisions to him. The article shows that the degree of bargaining interacts with the extent of product differentiation in determining whether the sub-game perfect Nash equilibrium is sales delegation, profit maximisation or, alternatively, pure-strategy multiple equilibria may emerge. We also show that when the weight of managerial power in determining managers' pay is relatively large, no delegation emerges at all 
(owners are profit maximisers) and the typical prisoner's dilemma of VFJS is solved. Importantly, this holds with both Cournot competition and Bertrand competition.

Results show that the established wisdom of the "classical" managerial delegation literature are no longer guaranteed when managers bargain over their contracts with owners (or boards of directors in large companies). In fact, under product substitutability, an increase in the extent of product differentiation tends to increase both production and firms' profits. Then, ceteris paribus, a manager should put a smaller effort to obtain a higher pay. Then, given a value of the extent of product differentiation, if the managerial bargaining power is fixed at too high a level, firms find it optimal to do not design a sales delegation contract to avoid reducing their profitability. In contrast, under product complementarity, a reduction in the extent of complementarity of products tend to reduce both production and firms' profits. Consequently, managers may reduce their effort in the bargaining process in order to obtain a higher pay because the benefit of sharing higher profits with the rival is reducing. Then, an exogenous shock that increases the managerial power works as disincentive device for the owner of each firm who does not want to design a sales delegation contract anymore, thus becoming a (Pareto efficient) profit maximiser. The article then points out the dependency of endogenous equilibrium outcomes of a delegation game on the relative bargaining power of owners and managers and the degree of product differentiation.

To the extent that the debate about executive remuneration is high in the business and policy worlds, and it is shared opinion that a bargaining over top management pay does exist between owners (or board of directors in large public companies) and managers, our article sheds a new light on the industrial and societal consequences of the use of sales delegation contracts. We note that the results of this article qualitatively hold also when the bargaining owner-manager includes full contract details (i.e., fixed wage, bonus rate and weight of the bonus), as in Kopel et al. (2016).

Importantly, several insights are also provided about equilibrium outcomes in quantity-setting and price-setting duopolies with heterogeneous managers in both contexts of exogenous and endogenous managerial bargaining power. In particular, when managers behave asymmetrically and the bargaining strength is exogenous, the main conclusions of the article are confirmed also for not too large asymmetries between managers' strength in the bargaining in which they are involved. Otherwise, there exist mixed equilibria in which only of the two firms hires a manager (who is the one with the lowest bargaining strength); whereas the rival behaves as a profit maximiser because his manager's bargaining strength is too large. When managers behave asymmetrically and the bargaining strength is endogenous, Cournot competition reveals that owners may hire managers with a positive bargaining strength at the equilibrium, whereas Bertrand competition implies that the owners always choose the incentive parameter in the managers' pay unilaterally.

Definitely, by considering the game theoretic approach (and the results) of VFJS as a benchmark, the conclusions of our article are twofold and divided in pars destruens and pars construens.

Pars destruens. Although the theory of VFJS has been extensively debated and used to explain the behaviours of managers in large corporations, its main conclusions (i.e., (S,S) is the sub-optimal Nash equilibrium of the game) hold only when products are homogeneous and the owner chooses the extent of the incentive parameter for managers in their remuneration scheme (sales delegation) unilaterally. However, this is at odds with the empirical evidence that products are generally differentiated (Mazzeo, 2002) and managers bargain their pay with owners (Bebchuk and Fried, 2003). Then, by accounting for these stylised facts, this theory is not able to explain how managers behave in a strategic context. This because the resulting Nash equilibrium of the game is (PM,PM) and this outcome can actually be Pareto efficient in either cases of Cournot and Bertrand rivalries for several parameter values. As far as products are heterogeneous and the bargaining power of the manager is sufficiently large, a firm is induced to do not delegate output decisions to chief executive officers. Indeed, product differentiation works exactly out in the direction of increasing the market power of a firm and reducing the need of strategic interaction with managerial (sales) delegation. This holds for a wide range of values of the bargaining power of the manager, i.e. with 
managers than behave more or less aggressively and in both cases of homogenous (symmetric behaviour) and heterogeneous (asymmetric behaviour) bargaining power.

Pars construens. Conclusions may change when the owner of a firm chooses endogenously the bargaining power of the manager he has to decide whether to hire or not to hire through profit maximisation. In that case, the game theoretic approach of VFJS is still able to explain the designing of sales delegation contracts for a wide range of values of the extent of product differentiation. Two different results emerge depending on whether competition in the output market occurs on quantity or price. In the former case, the owner of each firm finds it optimal to design a sales delegation contract with a positive managerial bargaining power at the equilibrium (which is set at a value that maximises firms' profits). This implies that under Cournot rivalry the owner and the manager design the incentive parameter in the delegation contract bilaterally. In the latter case, the owner of each firm finds it optimal to design a sales delegation contract with a null managerial bargaining power at the equilibrium. This implies that under Bertrand rivalry the owner without any negotiation with the manager designs the incentive parameter in the delegation contract unilaterally. Different from VFJS, however, there may exist multiple mixed Nash equilibrium in pure strategies corresponding to which one firm plays $\mathrm{S}$ and the rival plays PM.

Some questions should be addressed in future works in determining whether sales delegation contracts are designed or not. (1) The study of a bargaining model with different kinds of managerial contracts, such as relative profit delegation contracts (Miller and Pazgal, 2002) or market share delegation contracts (Jansen et al., 2007; Ritz, 2008). (2) The possibility of coalition formation between owners and managers in the case of heterogeneous bargaining power. (3) The interaction between managerial bargaining power and network externalities (Bhattacharjee and Pal, 2013; Chirco and Scrimitore, 2013). (4) The introduction of asymmetric and convex costs in the direction of the recent work of Fanti and Meccheri (2015). (5) Given the results presented in Appendix $\mathrm{C}$, which investigates the endogenous decisions by owners with respect to the bargaining powers of managers they will hire, further developments in this direction are indeed necessary, especially by considering different kinds of managerial contracts.

Acknowledgements The authors gratefully acknowledge an anonymous reviewer for valuable and stimulating comments on an earlier draft that have contributed to improve greatly the article. The usual disclaimer applies.

\section{Appendix A. Managerial influence on board of directors' decisions in Cournot and Bertrand duopolies}

In this appendix, we relax the hypothesis of the existence of a bargaining owner-manager over managerial compensation at the bargaining stage, and assumes the existence of a board of directors that may not be as independent of managers' influences as the owners might wish. This board of directors maximises (unilaterally) its own objective function at the contract stage of the game. This dependency is captured by following the arguments stated in Laux and Mittendorf (2011). Indeed, in actual firms the existence of a board of directors acting on behalf of owners is often observed. Therefore, it may be of importance to inquire about whether the results presented in the main text may change or not in a context when a board of directors represents owners.

A board of directors $(\mathrm{BoD})$ that may not be as independent as the owners might wish represents owners of each firm. We assume that the $\mathrm{BoD}$ (rather than the owner) of firm $i$ chooses $b_{i}$ by maximising the objective function $u_{i}^{B O D}=u_{i}^{O W N E R}+\delta u_{i}^{M A N A G E R}$ at the contract stage (rather than at the bargaining stage) of the game, where the non-negative parameter $\delta$ captures the weight of board's dependence on managerial decisions. Therefore, the $\mathrm{BoD}$ rather than the owners designs executive 
remuneration by maximising its own objective. By assuming that $u_{i}^{\text {OWNER }}=\Pi_{i}$ and $u_{i}^{\text {MANAGER }}:=u_{i}$ (see Eq. (5) in the main text), the sales delegation game is solved by knowing that the manager of firm $i$ is engaged in quantity-competition or price-competition with the manager of the rival firm at the market stage. By taking into account the solution of the game at this stage, the BoD of firm $i$ maximises $u_{i}^{B o D}$ with respect to $b_{i}$. Subsequently, the owner of firm $i$ chooses whether to hire a manager or not at the contract-bonus stage.

Below, we briefly present the results of this endogenous game for Cournot competition and Bertrand competition.

\section{A.1. Cournot competition}

Let $\delta_{\Delta_{1}}^{C}(d):=\frac{d^{2}\left(2-d^{2}\right)}{8} \geq 0$ for any $-1 \leq d \leq 1$,

$$
\begin{aligned}
& \delta_{\Delta_{2}}^{C}(d):=\frac{2}{3}-\frac{d^{2}}{4}+\frac{4-6 d^{2}}{3\left(-108 d^{4}+144 d^{2}-64+12 \sqrt{81 d^{8}-120 d^{6}+48 d^{4}}\right)^{1 / 3}}+ \\
& +\frac{\left(-108 d^{4}+144 d^{2}-64+12 \sqrt{81 d^{8}-120 d^{6}+48 d^{4}}\right)^{1 / 3}}{12} \geq 0
\end{aligned}
$$

for any $-1 \leq d \leq 1$ and $\delta_{\Delta_{3}}^{C}(d):=\frac{-d(4+3 d)}{4} \geq 0$ for any $-1 \leq d \leq 0$ be three threshold values of $\delta$ (under Cournot competition) such that profit differentials $\Delta_{1}^{C}=\Pi_{1}^{S / P M}-\Pi_{1}^{P M / P M}=0$, $\Delta_{2}^{C}=\Pi_{1}^{P M / S}-\Pi_{1}^{S / S}=0$ and $\Delta_{3}^{C}=\Pi_{1}^{P M / P M}-\Pi_{1}^{S / S}=0$, respectively. In addition, let $\delta_{T H}^{C}(d):=\frac{2-d^{2}}{4} \geq 0$ for any $-1 \leq d \leq 0$ be a threshold value of $\delta$ below that prices and profits are positive under Cournot competition. Then, the following proposition holds.

Proposition A.1. (a) [Cournot - product substitutability $(0 \leq d \leq 1)]$. (1) If $0 \leq \delta<\delta_{\Delta_{1}}^{C}$ (d) then (S,S) is the unique SPNE of the game and it is Pareto inefficient. (2) If $\delta_{\Delta_{1}}^{C}(d)<\delta<\delta_{\Delta_{2}}^{C}(d)$ then there exist two pure-strategy Nash equilibria, that is (S,S) and (PM,PM), but the former is payoff dominated by the latter. (3) If $\delta_{\Delta_{2}}^{C}(d)<\delta<\delta_{T H}^{C}(d)$ then (PM,PM) is the unique SPNE of the game and it is Pareto efficient.

(b) [Cournot - product complementarity $(-1 \leq d \leq 0)$ ]. (1) If $0 \leq \delta<\delta_{\Delta_{1}}^{C}(d)$ then $(\mathrm{S}, \mathrm{S})$ is the unique SPNE of the game and it is Pareto efficient. (2) If $\delta_{\Delta_{1}}^{C}(d)<\delta<\delta_{\Delta_{2}}^{C}(d)$ then there exist two purestrategy Nash equilibria, that is (S,S) and (PM,PM), but the former payoff dominates the latter. (3) If $\delta_{\Delta_{2}}^{C}(d)<\delta<\delta_{\Delta_{3}}^{C}(d)$ then (PM,PM) is the unique SPNE of the game and it is Pareto inefficient. (4) If $\delta_{\Delta_{3}}^{C}(d)<\delta<\delta_{T H}^{C}(d)$ then (PM,PM) is the unique SPNE of the game and it is Pareto efficient.

Proof. Profit differentials are the following:

$$
\begin{gathered}
\Delta_{1}^{C}=\frac{\left[d^{2}\left(2-d^{2}\right)-8 \delta\right]\left(d^{2}+4 \delta\right)}{8\left[2(1-\delta)-d^{2}\right]^{2}(2+d)^{2}}, \\
\Delta_{2}^{C}=\frac{\left(d^{2}+4 \delta\right)\left[64 \delta^{3}-16 \delta^{2}\left(8-d^{2}\right)+4 \delta\left(3 d^{4}-8 d^{2}+16\right)+d^{2}\left(d^{4}+8 d^{2}-16\right)\right]}{16\left[2(1-\delta)-d^{2}\right]^{2}[4(1-\delta)+d(2-d)]^{2}},
\end{gathered}
$$

and

$$
\Delta_{3}^{C}=\frac{[d(4+3 d)+4 \delta]\left(d^{2}+4 \delta\right)}{(2+d)^{2}[4(1-\delta)+d(2-d)]^{2}}
$$


The sign of $\Delta_{1}^{C}, \Delta_{2}^{C}$ and $\Delta_{3}^{C}$ changes depending on the relative position of the board dependence $\delta$ and the degree of product differentiation $d$. In the case of product substitutability $(0 \leq d \leq 1)$, it holds that $\Delta_{3}^{C}>0$ for any $0 \leq \delta<\delta_{T H}^{C}(d)$, and (1) if $0 \leq \delta<\delta_{\Delta_{1}}^{C}(d)$ then $\Delta_{1}^{C}>0$ and $\Delta_{2}^{C}<0$, (2) if $\delta_{\Delta_{1}}^{C}(d)<\delta<\delta_{\Delta_{2}}^{C}(d)$ then $\Delta_{1}^{C}<0$ and $\Delta_{2}^{C}<0$, (3) if $\delta_{\Delta_{2}}^{C}(d)<\delta<\delta_{T H}^{C}(d)$ then $\Delta_{1}^{C}<0$ and $\Delta_{2}^{C}>0$. Therefore, point (a) follows. In the case of product complementarity $(-1 \leq d \leq 0)$, it holds that (1) if $0 \leq \delta<\delta_{\Delta_{1}}^{C}(d)$ then $\Delta_{1}^{C}>0, \Delta_{2}^{C}<0$ and $\Delta_{3}^{C}<0$, (2) if $\delta_{\Delta_{1}}^{C}(d)<\delta<\delta_{\Delta_{2}}^{C}(d)$ then $\Delta_{1}^{C}<0, \Delta_{2}^{C}<0$ and $\Delta_{3}^{C}<0$, (3) if $\delta_{\Delta_{2}}^{C}(d)<\delta<\delta_{\Delta_{3}}^{C}(d)$ then $\Delta_{1}^{C}<0, \Delta_{2}^{C}>0$ and $\Delta_{3}^{C}<0$, (4) if $\delta_{\Delta_{3}}^{C}(d)<\delta<\delta_{T H}^{C}(d)$ then $\Delta_{1}^{C}<0, \Delta_{2}^{C}>0$ and $\Delta_{3}^{C}>0$. Therefore, point (b) follows. Q.E.D.

Corollary A.1. [Cournot - homogeneous products $(d=1)$ ]. (1) If $0 \leq \delta<0.125$ then there exists a unique SPNE, that is (S,S) and it is Pareto inefficient. (2) If $0.125<\delta<0.25=\delta_{T H}^{C}$ (1) then there exist two pure-strategy Nash equilibria, that is $(\mathrm{S}, \mathrm{S})$ and (PM,PM).

Proof. If $\quad d=1 \quad$ then $\quad \Delta_{1}^{C}=\frac{(1+4 \delta)(1-8 \delta)}{72(1-2 \delta)^{2}}, \quad \Delta_{2}^{C}=\frac{(1+4 \delta)(4 \delta-1)\left(16 \delta^{2}-16 \delta+7\right)}{16(1-2 \delta)^{2}(5-4 \delta)^{2}}<0 \quad$ and $\Delta_{3}^{C}=\frac{(7+4 \delta)(1+4 \delta)}{9(5-4 \delta)^{2}}>0$.

(1) If $0 \leq \delta<0.125$ then $\Delta_{1}^{C}>0, \quad \Delta_{2}^{C}<0$ and $\Delta_{3}^{C}>0$.

(2) If

$0.125<\delta<0.25=\delta_{T H}^{C}(1)$ then $\Delta_{1}^{C}<0, \Delta_{2}^{C}<0$ and $\Delta_{3}^{C}>0$. Q.E.D.

Figure A.1 summarises the results of Proposition A.1 and resembles Figures 1 and 2 in the main text. For any given value of $d$ values of $\delta$ larger than $\delta_{T H}^{C}(d)$ lead to an economically nonsensical scenario.

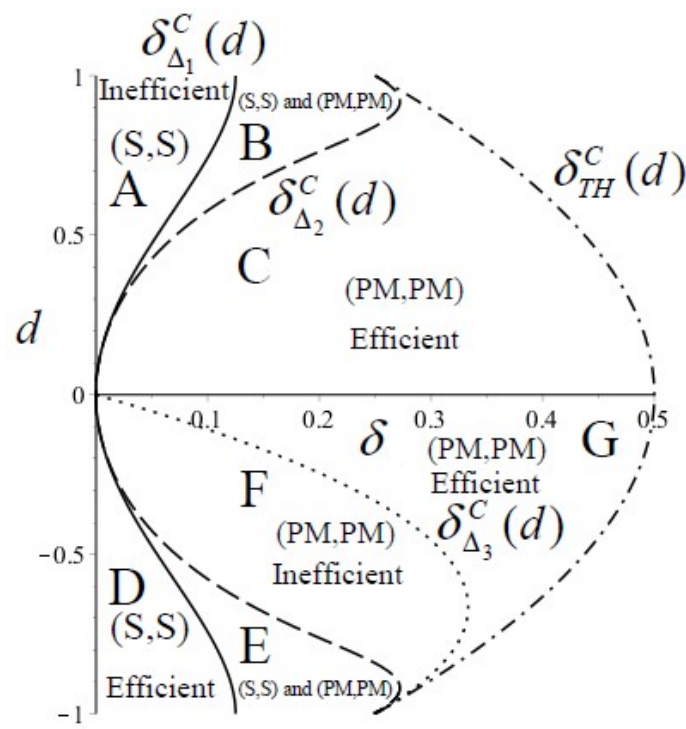

Figure A.1. The BoD game with quantity-setting firms. Profit differentials in $(\delta, d)$ space.

\section{A.2. Bertrand competition}

Let $\delta_{\Delta}^{B}(d):=\frac{d^{2}}{2\left(2-d^{2}\right)} \geq 0$ for any $-1 \leq d<1$ be a threshold value of $\delta$ (under Bertrand competition) such that profit differentials $\quad \Delta_{1}^{B}=\Pi_{1}^{S / P M}-\Pi_{1}^{P M / P M}=0, \quad \Delta_{2}^{B}=\Pi_{1}^{P M / S}-\Pi_{1}^{S / S}=0 \quad$ and 
$\Delta_{3}^{B}=\Pi_{1}^{P M / P M}-\Pi_{1}^{S / S}=0$. Let $\delta_{\Delta_{3}}^{B}(d):=\frac{-d(4-3 d)}{2(2-d)^{2}(1-d)^{2}}>\delta_{\Delta}^{B}(d) \geq 0$ for any $-1 \leq d \leq 0$ be a threshold value of $\delta$ such that $\Delta_{3}^{B}=\Pi_{1}^{P M / P M}-\Pi_{1}^{S / S}=0$. In addition, let $\delta_{T H}^{B}(d):=\frac{1}{2-d^{2}} \geq 0$ for any $-1 \leq d \leq 0$ be a threshold value of $\delta$ below that prices and profits are positive under Bertrand competition. Then, the following proposition holds.

Proposition A.2. (a) [Bertrand - product substitutability $(0 \leq d<1)$ ]. (1) If $0 \leq \delta<\delta_{\Delta}^{B}(d)$ then (S,S) is the unique SPNE of the game and it is Pareto efficient. (2) If $\delta_{\Delta}^{B}(d)<\delta<\delta_{T H}^{B}(d)$ then (PM,PM) is the unique SPNE of the game and it is Pareto efficient.

(b) [Bertrand - product complementarity $(-1 \leq d \leq 0)$ ]. (1) If $0 \leq \delta<\delta_{\Delta}^{B}(d)$ then $(\mathrm{S}, \mathrm{S})$ is the unique SPNE of the game and it is Pareto inefficient. (2) If $\delta_{\Delta}^{B}(d)<\delta<\delta_{\Delta_{3}}^{B}(d)$ then (PM,PM) is the unique SPNE of the game and it is Pareto inefficient. (3) If $\delta_{\Delta_{3}}^{B}(d)<\delta<\delta_{T H}^{B}(d)$ then (PM,PM) is the unique SPNE of the game and it is Pareto efficient.

Proof. Profit differentials are the following:

$$
\begin{gathered}
\Delta_{1}^{B}=\frac{(1-d)\left[4 \delta\left(1-d^{2}\right)+d^{2}\left(1+d^{2} \delta\right)\right]\left[d^{2}-2 \delta\left(2-d^{2}\right)\right]}{2(1+d)\left(2-d^{2}\right)(2-d)^{2}\left[2-\delta\left(2-d^{2}\right)\right]^{2}}, \\
\Delta_{2}^{B}=\frac{(1-d)\left[-d^{2}+2 \delta\left(2-d^{2}\right)\right]}{4(1+d)\left(2-d^{2}\right)^{2}\left[2(1-\delta)+d^{2} \delta\right]^{2}\left[4(1-\delta)-d(1-2 \delta)(2+d)-2 d \delta\left(2-d^{2}\right)\right]^{2}} \times \\
\times\left[\delta^{3}\left(-8 d^{10}+64 d^{8}-200 d^{6}+304 d^{4}-224 d^{2}+64\right)+\delta^{2}\left(-32 d^{8}+196 d^{6}-423 d^{4}+400 d^{2}-128\right)+,\right. \\
\left.+\delta\left(-38 d^{6}+156 d^{4}-192 d^{2}+64\right)+16 d^{2}-8 d^{4}-d^{6}\right]
\end{gathered}
$$

and

$$
\Delta_{3}^{B}=\frac{(1-d)\left[-d^{2}+2 \delta\left(2-d^{2}\right)\right]\left[d(4-3 d)+\delta\left(4-8 d+2 d^{2}+4 d^{3}-2 d^{4}\right)\right]}{(1+d)(2-d)^{2}\left[4(1-\delta)-d(1-2 \delta)(2+d)-2 d \delta\left(2-d^{2}\right)\right]^{2}} .
$$

The sign of $\Delta_{1}^{B}, \Delta_{2}^{B}$ and $\Delta_{3}^{B}$ change depending on the relative position of the degree of bargaining $k$ and the degree of product differentiation $d$. In the case of product substitutability $(0 \leq d<1)$, it holds that (1) if $0 \leq \delta<\delta_{\Delta}^{B}(d)$ then $\Delta_{1}^{B}>0, \Delta_{2}^{B}<0$ and $\Delta_{3}^{B}<0$, (2) if $\delta_{\Delta}^{B}(d)<\delta<\delta_{T H}^{B}(d)$ then $\Delta_{1}^{B}<0$, $\Delta_{2}^{B}>0$ and $\Delta_{3}^{B}>0$. Therefore, point (a) follows. In the case of product complementarity $(-1 \leq d \leq 0)$, it holds that (1) if $0 \leq \delta<\delta_{\Delta}^{B}(d)$ then $\Delta_{1}^{B}>0, \Delta_{2}^{B}<0$ and $\Delta_{3}^{B}>0$, (2) if $\delta_{\Delta}^{B}(d)<\delta<\delta_{\Delta_{3}}^{B}(d)$ then $\Delta_{1}^{B}<0, \Delta_{2}^{B}>0$ and $\Delta_{3}^{B}<0$, (3) if $\delta_{\Delta_{3}}^{B}(d)<\delta<\delta_{T H}^{B}(d)$ then $\Delta_{1}^{B}<0, \Delta_{2}^{B}>0$ and $\Delta_{3}^{B}>0$. Therefore, point (b) follows. Q.E.D.

Figure A.2 summarises the results of Proposition A. 2 and resembles Figures 3 and 4 in the main text. For any given value of $d$ values of $\delta$ larger than $\delta_{T H}^{B}(d)$ lead to an economically irrelevant scenario. 


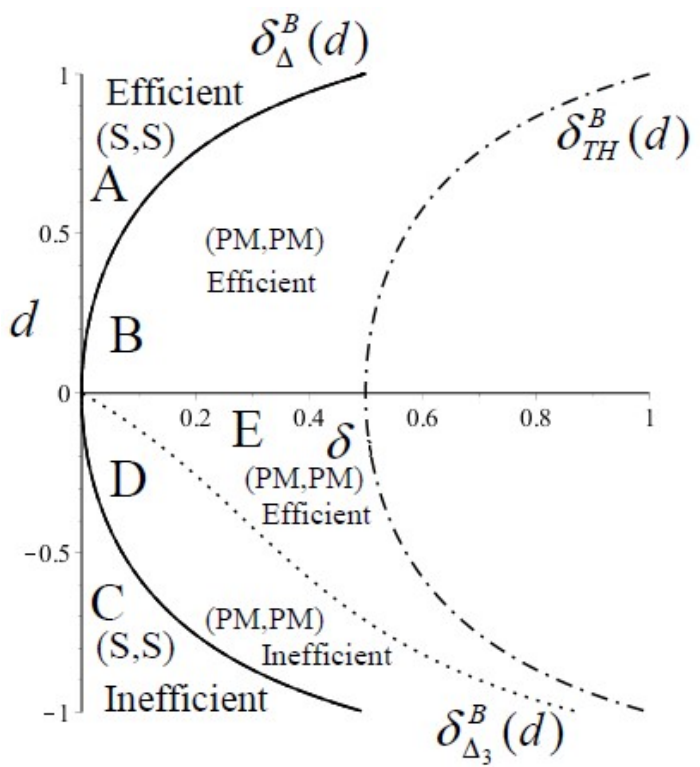

Figure A.2. The BoD game with price-setting firms. Profit differentials in $(\delta, d)$ space.

\section{Appendix B. Heterogeneous managerial bargaining power}

In the main text, we have built on a game with quantity- or price-setting firms in which the choice of whether hiring a manager or not hiring him is endogenous for the owner of each firm. In a context with symmetric managerial bargaining power, we have shown that for any given value of the extent of product differentiation, the owner does not hire the manager (alternatively, he hires a manager and let him behave just like a profit maximiser) when his bargaining power is sufficiently large. Of course, it would be more realistic to consider heterogeneous managers that behave asymmetrically in the Nash bargaining with their own owner. This because in real life cases there may exist various kinds of managers' person(ality), for instance with regard to their personal attitudes towards the effects of investments and demand conditions. ${ }^{14}$ Moreover, managers can also be distinguished between them depending on their personal abilities to bargain with the owners (i.e., they may behave more or less aggressively in the bargaining). Then, in order to capture this feature, we now relax the assumption of homogeneous bargaining power and treat the more general case with heterogeneous managers under Cournot and Bertrand competition. We note that owners do not know the manager's attitude at the time of recruiting (we will relax this assumption in Appendix C, where we will consider a model in which owners are aware of the manager's attitude at the time of recruiting, and they hire a manager whose strength is the one that maximises owners' profits).

From a modelling point of view, under the assumption of heterogeneous managerial bargaining power, the main difference that emerges in comparison with the case of homogeneous bargaining power (see Eq. (15) in the main text) is captured by the following equation:

$$
\mathrm{N}_{i}=u_{i}^{k_{i}} \Pi_{i}^{1-k_{i}} \text {, }
$$

where $0 \leq k_{i}<1$ is the relative bargaining power of the manager of type or strength $i$, who is exactly the one hired by firm $i(i=1,2)$. Eq. (B.1) implies that firm $i$ and manager of strength $i$ negotiate about the extent of the incentive parameter $b_{i}$ in managerial pay.

\footnotetext{
${ }^{14}$ In the terminology of Englmaier (2011), managers may be over/under optimistic or, alternatively, over/under
} confident. 


\section{B.1. Cournot competition}

The backward induction logic implies that to solve the game we should use a line of reasoning backwards in time (that is, from the end to the beginning of a problem) to determine a sequence of optimal actions. Therefore, under Cournot competition, knowing that managers have to choose the quantity in the output market (given $b_{i}$ and $k_{i}$ ) and there exists a Nash bargaining between owner $i$ and manager $i$ to choose $b_{i}$, Tables B.1 and B.2 summarise equilibrium outcomes with regard to quantities and profits, respectively, in all cases of uniform and mixed behaviours.

\begin{tabular}{|c|c|c|}
\hline Firm 1 & $\begin{array}{c}\text { PM } \\
\text { (Cournot) }\end{array}$ & $\begin{array}{c}\text { S } \\
\text { (Cournot) }\end{array}$ \\
\hline $\begin{array}{c}\text { PM } \\
\text { (Cournot) }\end{array}$ & $q_{1}^{P M / P M}, q_{2}^{P M / P M}$ & $q_{1}^{P M / S}, q_{2}^{P M / S}$ \\
\hline $\begin{array}{c}\text { S } \\
\text { (Cournot) }\end{array}$ & $q_{1}^{S / P M}, q_{2}^{S / P M}$ & $q_{1}^{S / S}, q_{2}^{S / S}$ \\
\hline
\end{tabular}

Table B.1. Quantities of firm 1 and firm 2 under sales delegation (S) and profit maximisation (PM) with Cournot competition and heterogeneous managers.

The entries of Table B.1 are the following:

$$
\begin{gathered}
q_{1}^{P M / P M}=q_{2}^{P M / P M}=\frac{1}{2+d}, \\
q_{1}^{S / S}=\frac{2\left(1+k_{1}\right)\left[4-d^{2}\left(1-k_{2}\right)-2 d\left(1+k_{2}\right)\right]}{16+d^{4}\left(1-k_{1}\right)\left(1-k_{2}\right)-4 d^{2}\left(3+k_{1} k_{2}\right)}, \\
q_{2}^{S / S}=\frac{2\left(1+k_{2}\right)\left[4-d^{2}\left(1-k_{1}\right)-2 d\left(1+k_{1}\right)\right]}{16+d^{4}\left(1-k_{1}\right)\left(1-k_{2}\right)-4 d^{2}\left(3+k_{1} k_{2}\right)}, \\
q_{1}^{S / P M}=\frac{(2-d)\left(1+k_{1}\right)}{2\left(2-d^{2}\right)}, \\
q_{2}^{S / P M}=\frac{4-d^{2}\left(1-k_{1}\right)-2 d\left(1+k_{1}\right)}{4\left(2-d^{2}\right)}, \\
q_{1}^{P M / S}=\frac{4-d^{2}\left(1-k_{2}\right)-2 d\left(1+k_{2}\right)}{4\left(2-d^{2}\right)},
\end{gathered}
$$

and

$$
q_{2}^{P M / S}=\frac{(2-d)\left(1+k_{2}\right)}{2\left(2-d^{2}\right)}
$$

\begin{tabular}{|c|c|c|}
\hline Firm 1 & $\begin{array}{c}\text { PM } \\
\text { (Cournot) }\end{array}$ & $\begin{array}{c}\text { S } \\
\text { (Cournot) }\end{array}$ \\
\hline $\begin{array}{c}\text { PM } \\
\text { (Cournot) }\end{array}$ & $\Pi_{1}^{P M / P M}, \Pi_{2}^{P M / P M}$ & $\Pi_{1}^{P M / S}, \Pi_{2}^{P M / S}$ \\
\hline $\begin{array}{c}\text { S } \\
\text { (Cournot) }\end{array}$ & $\Pi_{1}^{S / P M}, \Pi_{2}^{S / P M}$ & $\Pi_{1}^{S / S}, \Pi_{2}^{S / S}$ \\
\hline
\end{tabular}

Table B.2. Payoff matrix: profits under sales delegation (S) and profit maximisation (PM) with Cournot competition and heterogeneous managers.

The entries of Table B. 2 are the following: 


$$
\begin{gathered}
\Pi_{1}^{P M / P M}=\Pi_{2}^{P M / P M}=\frac{1}{(2+d)^{2}}, \\
\Pi_{1}^{S / S}=\frac{2\left(1-k_{1}\right)\left(1+k_{1}\right)\left(2-d^{2}\right)\left[4-d^{2}\left(1-k_{2}\right)-2 d\left(1+k_{2}\right)\right]^{2}}{\left[16+d^{4}\left(1-k_{1}\right)\left(1-k_{2}\right)-4 d^{2}\left(3+k_{1} k_{2}\right)\right]^{2}} \\
\Pi_{2}^{S / S}=\frac{2\left(1-k_{2}\right)\left(1+k_{2}\right)\left(2-d^{2}\right)\left[4-d^{2}\left(1-k_{1}\right)-2 d\left(1+k_{1}\right)\right]^{2}}{\left[16+d^{4}\left(1-k_{1}\right)\left(1-k_{2}\right)-4 d^{2}\left(3+k_{1} k_{2}\right)\right]^{2}} \\
\Pi_{1}^{S / P M}=\frac{(2-d)^{2}\left(1-k_{1}\right)\left(1+k_{1}\right)}{8\left(2-d^{2}\right)} \\
\Pi_{2}^{S / P M}=\frac{\left[4-d^{2}\left(1-k_{1}\right)-2 d\left(1+k_{1}\right)\right]^{2}}{16\left(2-d^{2}\right)^{2}} \\
\Pi_{1}^{P M / S}=\frac{\left[4-d^{2}\left(1-k_{2}\right)-2 d\left(1+k_{2}\right)\right]^{2}}{16\left(2-d^{2}\right)^{2}}
\end{gathered}
$$

and

$$
\Pi_{2}^{P M / S}=\frac{(2-d)^{2}\left(1-k_{2}\right)\left(1+k_{2}\right)}{8\left(2-d^{2}\right)} .
$$

We now present directly the proposition that summarises the results regarding the outcomes of a bargaining-sales-delegation game with Cournot competition and asymmetric managerial behaviour under product substitutability and product complementarity. Before doing this, let

$$
k_{1, \Delta_{1,1}}^{C}(d)=k_{2, \Delta_{1,2}}^{C}(d):=\frac{d^{2}}{4-d^{2}} \geq 0,
$$

for any $-1 \leq d \leq 1$, be a threshold value of $k_{1}$ and $k_{2}$ such that profit differentials $\Delta_{1,1}^{C}=\Pi_{1}^{S / P M}-\Pi_{1}^{P M / P M}=0$ and $\Delta_{1,2}^{C}=\Pi_{2}^{P M / S}-\Pi_{2}^{P M / P M}=0$ (the second subscript identifies the firm).

Let also

$$
k_{1, \Delta_{2,1}}^{C}\left(k_{2}, d\right):=\frac{d^{2}\left[16\left(1+2 k_{2}\right)-d^{4}\left(1-k_{2}\right)^{2}-8 d^{2}\left(1+3 k_{2}\right)\right]}{64-d^{6}\left(1-k_{2}\right)^{2}+4 d^{4}\left(7+k_{2}^{2}\right)-80 d^{2}} \geq 0,
$$

for any $-1 \leq d \leq 1$ and $0 \leq k_{2}<1$, and

$$
k_{2, \Delta_{2,2}}^{C}\left(k_{1}, d\right):=\frac{d^{2}\left[16\left(1+2 k_{1}\right)-d^{4}\left(1-k_{1}\right)^{2}-8 d^{2}\left(1+3 k_{1}\right)\right]}{64-d^{6}\left(1-k_{1}\right)^{2}+4 d^{4}\left(7+k_{1}^{2}\right)-80 d^{2}} \geq 0,
$$

for any $-1 \leq d \leq 1$ and $0 \leq k_{1}<1$, be two threshold values of $k_{1}$ and $k_{2}$ such that profit differentials $\Delta_{2,1}^{C}=\Pi_{1}^{P M / S}-\Pi_{1}^{S / S}=0$ and $\Delta_{2,2}^{C}=\Pi_{2}^{S / P M}-\Pi_{2}^{S / S}=0$, respectively. As is known, through the analysis of these profit differentials we may obtain any possible Nash equilibrium configuration of the game. Then, the following proposition holds.

Proposition B.1. (a) [Cournot - product substitutability $(0 \leq d \leq 1)$ ]. (1) Let $0 \leq k_{2}<k_{2, \Delta_{1,2}}^{C}$ (d) hold. (1.1) If $0 \leq k_{1}<k_{1, \Delta_{1,1}}^{C}(d)$ then $(\mathrm{S}, \mathrm{S})$ is the unique SPNE of the game. (1.2) If $k_{1, \Delta_{1,1}}^{C}(d)<k_{1}<k_{1, \Delta_{2,1}}^{C}\left(k_{2}, d\right)$ then (S,S) is the unique SPNE of the game. (1.3) If $k_{1, \Delta_{2,1}}^{C}\left(k_{2}, d\right)<k_{1}<1$ then $(\mathrm{PM}, \mathrm{S})$ is the unique mixed SPNE of the game. (2) Let $k_{2, \Delta_{1,2}}^{C}(d)<k_{2}<k_{2, \Delta_{2,2}}^{C}\left(k_{1}, d\right)$ hold. (2.1) If $0 \leq k_{1}<k_{1, \Delta_{1,1}}^{C}(d)$ then (S,S) is the unique SPNE of the game. (2.2) If $k_{1, \Delta_{1,1}}^{C}(d)<k_{1}<k_{1, \Delta_{2,1}}^{C}\left(k_{2}, d\right)$ then there exist two pure-strategy Nash equilibria, that is (S,S) and (PM,PM), but the former is payoff dominated by the latter. (2.3) If $k_{1, \Delta_{2,1}}^{C}\left(k_{2}, d\right)<k_{1}<1$ then (PM,PM) is the unique SPNE of the game. (3) Let $k_{2, \Delta_{2,2}}^{C}\left(k_{1}, d\right)<k_{2}<1$ hold. (3.1) If $0 \leq k_{1}<k_{1, \Delta_{1,1}}^{C}(d)$ then (S,PM) is the unique mixed SPNE of 
the game. (3.2) If $k_{1, \Delta_{1,1}}^{C}(d)<k_{1}<k_{1, \Delta_{2,1}}^{C}\left(k_{2}, d\right)$ then (PM,PM) is the unique SPNE of the game. (3.3) If $k_{1, \Delta_{2,1}}^{C}\left(k_{2}, d\right)<k_{1}<1$ then (PM,PM) is the unique SPNE of the game.

(b) [Cournot - product complementarity $(-1 \leq d \leq 0)$ ]. (1) Let $0 \leq k_{2}<k_{2, \Delta_{1,2}}^{C}(d)$ hold. (1.1) If $0 \leq k_{1}<k_{1, \Delta_{1,1}}^{C}(d)$ then (S,S) is the unique SPNE of the game. (1.2) If $k_{1, \Delta_{1,1}}^{C}(d)<k_{1}<k_{1, \Delta_{2,1}}^{C}\left(k_{2}, d\right)$ then (S,S) is the unique SPNE of the game. (1.3) If $k_{1, \Delta_{2,1}}^{c}\left(k_{2}, d\right)<k_{1}<1$ then (PM,S) is the unique mixed SPNE of the game. (2) Let $k_{2, \Delta_{1,2}}^{C}(d)<k_{2}<k_{2, \Delta_{2,2}}^{C}\left(k_{1}, d\right)$ hold. (2.1) If $0 \leq k_{1}<k_{1, \Delta_{1,1}}^{C}(d)$ then (S,S) is the unique SPNE of the game. (2.2) If $k_{1, \Delta_{1,1}}^{C}(d)<k_{1}<k_{1, \Delta_{2,1}}^{C}\left(k_{2}, d\right)$ then there exist two pure-strategy Nash equilibria, that is $(\mathrm{S}, \mathrm{S})$ and $(\mathrm{PM}, \mathrm{PM})$, but the former payoff dominates the latter. (2.3) If $k_{1, \Delta_{2,1}}^{C}\left(k_{2}, d\right)<k_{1}<1$ then (PM,PM) is the unique SPNE of the game. (3) Let $k_{2, \Delta_{2,2}}^{C}\left(k_{1}, d\right)<k_{2}<1$ hold. (3.1) If $0 \leq k_{1}<k_{1, \Delta_{1,1}}^{C}(d)$ then (S,PM) is the unique mixed SPNE of the game. (3.2) If $k_{1, \Delta_{1,1}}^{C}(d)<k_{1}<k_{1, \Delta_{2,1}}^{C}\left(k_{2}, d\right)$ then (PM,PM) is the unique SPNE of the game. (3.3) If $k_{1, \Delta_{2,1}}^{C}\left(k_{2}, d\right)<k_{1}<1$ then (PM,PM) is the unique SPNE of the game.

Proof. Profit differentials are the following:

$$
\begin{aligned}
& \Delta_{1,1}^{C}=\frac{\left[d^{2}-k_{1}\left(4-d^{2}\right)\right]\left[d^{2}+k_{1}\left(4-d^{2}\right)\right]}{8\left(2-d^{2}\right)(2+d)^{2}}, \quad \Delta_{1,2}^{C}=\frac{\left[d^{2}-k_{2}\left(4-d^{2}\right)\right]\left[d^{2}+k_{2}\left(4-d^{2}\right)\right]}{8\left(2-d^{2}\right)(2+d)^{2}} \\
& \Delta_{2,1}^{C}=\frac{\left[d^{2}+k_{1}\left(4-d^{2}\right)\right]\left[4-d^{2}\left(1-k_{2}\right)-2 d\left(1+k_{2}\right)\right]^{2}}{16\left(2-d^{2}\right)^{2}\left[16+d^{4}\left(1-k_{1}\right)\left(1-k_{2}\right)-4 d^{2}\left(3+k_{1} k_{2}\right)\right]^{2}} \times \\
& \times\left\{k_{1}\left[64-80 d^{2}+4 d^{4}\left(7+k_{2}^{2}\right)-d^{6}\left(1-k_{2}\right)^{2}\right]-16 d^{2}\left(1+2 k_{2}\right)+8 d^{4}\left(1+3 k_{2}\right)+d^{6}\left(1-k_{2}\right)^{2}\right\}
\end{aligned}
$$

and

$$
\begin{aligned}
& \Delta_{2,2}^{C}=\frac{\left[d^{2}+k_{2}\left(4-d^{2}\right)\right]\left[4-d^{2}\left(1-k_{1}\right)-2 d\left(1+k_{1}\right)\right]^{2}}{16\left(2-d^{2}\right)^{2}\left[16+d^{4}\left(1-k_{1}\right)\left(1-k_{2}\right)-4 d^{2}\left(3+k_{1} k_{2}\right)\right]^{2}} \times \\
& \times\left\{k_{2}\left[64-80 d^{2}+4 d^{4}\left(7+k_{1}^{2}\right)-d^{6}\left(1-k_{1}\right)^{2}\right]-16 d^{2}\left(1+2 k_{1}\right)+8 d^{4}\left(1+3 k_{1}\right)+d^{6}\left(1-k_{1}\right)^{2}\right\}
\end{aligned}
$$

The sign of $\Delta_{1,1}^{C}, \Delta_{1,2}^{C}, \Delta_{2,1}^{C}$ and $\Delta_{2,2}^{C}$ changes depending on the relative position of $k_{1}$ and $k_{2}$ for any given value of $d$. In either cases of product substitutability $(0 \leq d \leq 1)$ and complementarity $(-1 \leq d \leq 0)$, it holds for any $0 \leq k_{2}<k_{2, \Delta_{1,2}}^{C}(d)$ that (1.1) if $0 \leq k_{1}<k_{1, \Delta_{1,1}}^{C}(d)$ then $\Delta_{1,1}^{C}>0, \Delta_{2,1}^{C}<0$, $\Delta_{1,2}^{C}>0$ and $\Delta_{2,2}^{C}<0,(1.2)$ if $k_{1, \Delta_{1,1}}^{C}(d)<k_{1}<k_{1, \Delta_{2,1}}^{C}\left(k_{2}, d\right)$ then $\Delta_{1,1}^{C}<0, \Delta_{2,1}^{C}<0, \Delta_{1,2}^{C}>0$ and $\Delta_{2,2}^{C}<0$, (1.3) if $k_{1, \Delta_{2,1}}^{C}\left(k_{2}, d\right)<k_{1}<1 \quad$ then $\Delta_{1,1}^{C}<0, \quad \Delta_{2,1}^{C}>0, \quad \Delta_{1,2}^{C}>0 \quad$ and $\quad \Delta_{2,2}^{C}<0$; for any $k_{2, \Delta_{1,2}}^{C}(d)<k_{2}<k_{2, \Delta_{2,2}}^{C}\left(k_{1}, d\right)$ that (2.1) if $0 \leq k_{1}<k_{1, \Delta_{1,1}}^{C}(d)$ then $\Delta_{1,1}^{C}>0, \Delta_{2,1}^{C}<0, \Delta_{1,2}^{C}<0$ and $\Delta_{2,2}^{C}<0$, (2.2) if $k_{1, \Delta_{1,1}}^{C}(d)<k_{1}<k_{1, \Delta_{2,1}}^{C}\left(k_{2}, d\right) \quad$ then $\Delta_{1,1}^{C}<0, \quad \Delta_{2,1}^{C}<0, \quad \Delta_{1,2}^{C}<0 \quad$ and $\quad \Delta_{2,2}^{C}<0, \quad$ (2.3) if $k_{1, \Delta_{2,1}}^{C}\left(k_{2}, d\right)<k_{1}<1$ then $\Delta_{1,1}^{C}<0, \Delta_{2,1}^{C}>0, \Delta_{1,2}^{C}<0$ and $\Delta_{2,2}^{C}<0$; for any $k_{2, \Delta_{2,2}}^{C}\left(k_{1}, d\right)<k_{2}<1$ that (3.1) if $0 \leq k_{1}<k_{1, \Delta_{1,1}}^{C}(d)$ then $\Delta_{1,1}^{C}>0, \Delta_{2,1}^{C}<0, \Delta_{1,2}^{C}<0$ and $\Delta_{2,2}^{C}>0$, (3.2) if $k_{1, \Delta_{1,1}}^{C}(d)<k_{1}<k_{1, \Delta_{2,1}}^{C}\left(k_{2}, d\right)$ then $\Delta_{1,1}^{C}<0, \Delta_{2,1}^{C}<0, \Delta_{1,2}^{C}<0$ and $\Delta_{2,2}^{C}>0$, (3.3) if $k_{1, \Delta_{2,1}}^{C}\left(k_{2}, d\right)<k_{1}<1$ then $\Delta_{1,1}^{C}<0, \Delta_{2,1}^{C}>0, \Delta_{1,2}^{C}<0$ and $\Delta_{2,2}^{C}>0$. Q.E.D.

Figure B.1 shows the different regions in which the outcome of this asymmetric Cournot game changes depending on the relative strength of manager 1 and manager 2 in the bargaining with owner 1 and owner 2, respectively. It reveals that conclusions are in line with the case of homogeneous managerial bargaining power explored in the main text. Indeed, in either case of product substitutability and complementarity, the owner of each firm plays PM when the bargaining power of his manager is sufficiently large. Along the main diagonal (not reported in the figure), we 
have that $k_{1}=k_{2}$ so that the model boils down to the case of homogeneous managers whose results are those analysed and discussed previously. The outcomes of the game with homogenous bargaining power are robust for not too large asymmetries between managers' strength in the bargaining in which they are involved. The figure is depicted for $d=0.8$ (substitutability) and $d=-0.8$ (complementarity) for reasons of expository clarity. Of course, the shape of the diagram depicted in the figure qualitatively holds for the whole range of values of the parameter capturing the extent of product differentiation, i.e. $-1 \leq d \leq 1$.

A complete characterisation of the Pareto efficiency/inefficiency of the various outcomes of the asymmetric game may be quite long and then we do not proceed further into the analysis at this stage. However, numerical examples not reported in the paper reveal that for couples $\left(k_{1}, k_{2}\right)$ such that $(\mathrm{PM}, \mathrm{PM})($ resp. $(\mathrm{S}, \mathrm{S})$ ) is the unique SPNE of the game under product substitutability (resp. complementarity), this outcome is Pareto efficient.

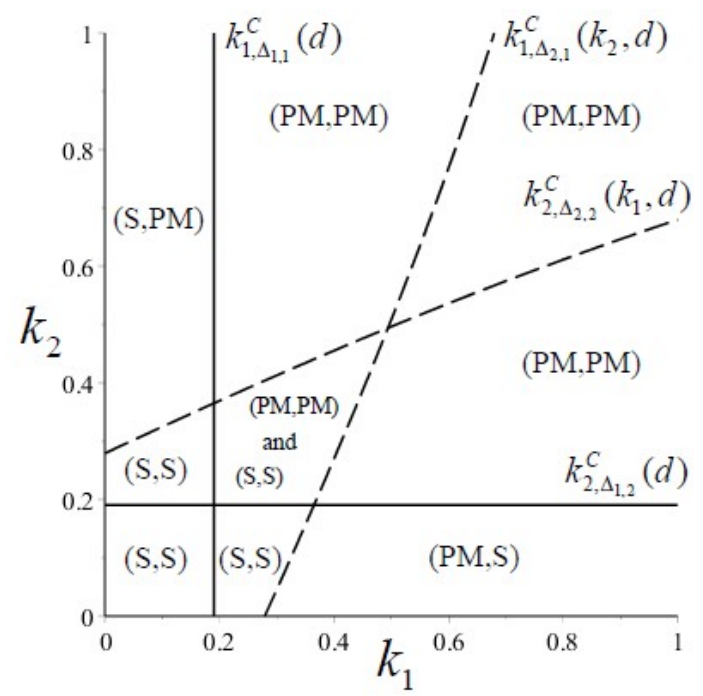

Figure B.1. The bargaining-sales-delegation game with asymmetric managerial behaviour. Profit differentials in $\left(k_{1}, k_{2}\right)$ space under Cournot competition in the case of product substitutability $(d=0.8)$ and product complementarity $(d=-0.8)$.

\section{B.2. Bertrand competition}

The Bertrand competition game with asymmetric managerial bargaining power is quite similar to the Cournot competition game analysed in the previous section of the present appendix, with the only difference that the managers compete on prices. Therefore, Tables B.3 and B.4 summarise equilibrium outcomes with regard to prices and profits, respectively, in all cases of uniform and mixed behaviours under Bertrand rivalries.

\begin{tabular}{|c|c|c|}
\hline Firm 2 & $\begin{array}{c}\text { PM } \\
\text { (Bertrand) }\end{array}$ & $\begin{array}{c}\mathrm{S} \\
\text { (Bertrand) }\end{array}$ \\
\hline $\begin{array}{c}\text { PM } \\
\text { (Bertrand) }\end{array}$ & $p_{1}^{P M / P M}, p_{2}^{P M / P M}$ & $p_{1}^{P M / S}, p_{2}^{P M / S}$ \\
\hline $\begin{array}{c}\mathrm{S} \\
\text { (Bertrand) }\end{array}$ & $p_{1}^{S / P M}, p_{2}^{S / P M}$ & $p_{1}^{S / S}, p_{2}^{S / S}$ \\
\hline
\end{tabular}

Table B.3. Prices of firm 1 and firm 2 under sales delegation (S) and profit maximisation (PM) with Bertrand competition and heterogeneous managers.

The entries of Table B.3 are the following: 


$$
\begin{gathered}
p_{1}^{P M / P M}=p_{2}^{P M / P M}=\frac{1-d}{2-d}, \\
p_{1}^{S / S}=\frac{2(1-d)\left(1-k_{1}\right)\left[4-d^{2}\left(1+k_{2}\right)+2 d\left(1-k_{2}\right)\right]}{16+d^{4}\left(1+k_{1}\right)\left(1+k_{2}\right)-4 d^{2}\left(3+k_{1} k_{2}\right)}, \\
p_{2}^{S / S}=\frac{2(1-d)\left(1-k_{2}\right)\left[4-d^{2}\left(1+k_{1}\right)+2 d\left(1-k_{1}\right)\right]}{16+d^{4}\left(1+k_{1}\right)\left(1+k_{2}\right)-4 d^{2}\left(3+k_{1} k_{2}\right)}, \\
p_{1}^{S / P M}=\frac{(1-d)(2+d)\left(1-k_{1}\right)}{2\left(2-d^{2}\right)}, \\
p_{2}^{S / P M}=\frac{(1-d)\left[4-d^{2}\left(1+k_{1}\right)+2 d\left(1-k_{1}\right)\right]}{4\left(2-d^{2}\right)}, \\
p_{1}^{P M / S}=\frac{(1-d)\left[4-d^{2}\left(1+k_{2}\right)+2 d\left(1-k_{2}\right)\right]}{4\left(2-d^{2}\right)},
\end{gathered}
$$

and

$$
p_{2}^{P M / S}=\frac{(1-d)(2+d)\left(1-k_{2}\right)}{2\left(2-d^{2}\right)} .
$$

\begin{tabular}{|c|c|c|}
\hline Firm 1 & $\begin{array}{c}\text { PM } \\
\text { (Bertrand) }\end{array}$ & $\begin{array}{c}\text { S } \\
\text { (Bertrand) }\end{array}$ \\
\hline $\begin{array}{c}\text { PM } \\
\text { (Bertrand) }\end{array}$ & $\Pi_{1}^{P M / P M}, \Pi_{2}^{P M / P M}$ & $\Pi_{1}^{P M / S}, \Pi_{2}^{P M / S}$ \\
\hline $\begin{array}{c}\text { S } \\
\text { (Bertrand) }\end{array}$ & $\Pi_{1}^{S / P M}, \Pi_{2}^{S / P M}$ & $\Pi_{1}^{S / S}, \Pi_{2}^{S / S}$ \\
\hline
\end{tabular}

Table B.4. Payoff matrix: profits under sales delegation (S) and profit maximisation (PM) with Cournot competition and heterogeneous managers.

The entries of Table B.4 are the following:

$$
\begin{gathered}
\Pi_{1}^{P M / P M}=\Pi_{2}^{P M / P M}=\frac{(1-d)^{2}}{\left(1-d^{2}\right)(2-d)^{2}}, \\
\Pi_{1}^{S / S}=\frac{2(1-d)\left(2-d^{2}\right)\left(1-k_{1}\right)\left(1+k_{1}\right)\left[4-d^{2}\left(1+k_{2}\right)+2 d\left(1-k_{2}\right)\right]^{2}}{(1+d)\left[16+d^{4}\left(1+k_{1}\right)\left(1+k_{2}\right)-4 d^{2}\left(3+k_{1} k_{2}\right)\right]^{2}} \\
\Pi_{2}^{S / S}=\frac{2(1-d)\left(2-d^{2}\right)\left(1-k_{2}\right)\left(1+k_{2}\right)\left[4-d^{2}\left(1+k_{1}\right)+2 d\left(1-k_{1}\right)\right]^{2}}{(1+d)\left[16+d^{4}\left(1+k_{1}\right)\left(1+k_{2}\right)-4 d^{2}\left(3+k_{1} k_{2}\right)\right]^{2}}, \\
\Pi_{1}^{S / P M}=\frac{(1-d)(2+d)^{2}\left(1-k_{1}\right)\left(1+k_{1}\right)}{8(1+d)\left(2-d^{2}\right)}, \\
\Pi_{2}^{S / P M}=\frac{(1-d)\left[4-d^{2}\left(1+k_{1}\right)+2 d\left(1-k_{1}\right)\right]^{2}}{16(1+d)\left(2-d^{2}\right)^{2}}, \\
\Pi_{1}^{P M / S}=\frac{(1-d)\left[4-d^{2}\left(1+k_{2}\right)+2 d\left(1-k_{2}\right)\right]^{2}}{16(1+d)\left(2-d^{2}\right)^{2}},
\end{gathered}
$$

and

$$
\Pi_{2}^{P M / S}=\frac{(1-d)(2+d)^{2}\left(1-k_{2}\right)\left(1+k_{2}\right)}{8(1+d)\left(2-d^{2}\right)} .
$$

Let 


$$
k_{\Delta}^{B}(d):=k_{1, \Delta_{1,1}}^{B}(d)=k_{2, \Delta_{1,2}}^{B}(d)=k_{1, \Delta_{2,1}}^{B}(d)=k_{2, \Delta_{2,2}}^{B}(d):=\frac{d^{2}}{4-d^{2}}=k_{1, \Delta_{1,1}}^{C}(d)=k_{2, \Delta_{1,2}}^{C}(d) \geq 0,
$$

for any $-1 \leq d \leq 1$, be a threshold value of $k_{1}$ and $k_{2}$ such that profit differentials $\Delta_{1,1}^{B}=\Pi_{1}^{S / P M}-\Pi_{1}^{P M / P M}=0, \quad \Delta_{1,2}^{B}=\Pi_{2}^{P M / S}-\Pi_{2}^{P M / P M}=0, \quad \Delta_{2,1}^{B}=\Pi_{1}^{P M / S}-\Pi_{1}^{S / S}=0 \quad$ and $\Delta_{2,2}^{B}=\Pi_{2}^{S / P M}-\Pi_{2}^{S / S}=0$ (the second subscript identifies the firm). The following proposition summarises the results regarding the outcomes of a bargaining-sales-delegation game with Bertrand competition and asymmetric managerial behaviour under product substitutability and product complementarity.

Proposition B.2. (a) [Bertrand - product substitutability $(0 \leq d \leq 1)$ and product complementarity $(-1 \leq d \leq 0)$ ]. (1) Let $0 \leq k_{2}<k_{2, \Delta_{1,2}}^{B}(d)$ hold. (1.1) If $0 \leq k_{1}<k_{1, \Delta_{1,1}}^{B}(d)$ then (S,S) is the unique SPNE of the game. (1.2) If $k_{1, \Delta_{1,1}}^{c}(d)<k_{1}<1$ then (PM,S) is the unique mixed SPNE of the game. (2) Let $k_{2, \Delta_{1,2}}^{C}(d)<k_{2}<1$ hold. (2.1) If $0 \leq k_{1}<k_{1, \Delta_{1,1}}^{C}(d)$ then (S,PM) is the unique mixed SPNE of the game. (2.2) If $k_{1, \Delta_{1,1}}^{C}(d)<k_{1}<1$ then (PM,PM) is the unique SPNE of the game.

Proof. Profit differentials are the following:

$$
\begin{gathered}
\Delta_{1,1}^{B}=\frac{(1-d)\left[d^{2}-k_{1}\left(4-d^{2}\right)\right]\left[d^{2}+k_{1}\left(4-d^{2}\right)\right]}{8(1+d)\left(2-d^{2}\right)(2-d)^{2}}, \quad \Delta_{1,2}^{B}=\frac{(1-d)\left[d^{2}-k_{2}\left(4-d^{2}\right)\right]\left[d^{2}+k_{2}\left(4-d^{2}\right)\right]}{8(1+d)\left(2-d^{2}\right)(2-d)^{2}} \\
\Delta_{2,1}^{B}=\frac{(1-d)\left[d^{2}-k_{1}\left(4-d^{2}\right)\right]\left[4-d^{2}\left(1+k_{2}\right)+2 d\left(1-k_{2}\right)\right]^{2}}{16(1+d)\left(2-d^{2}\right)^{2}\left[16+d^{4}\left(1+k_{1}\right)\left(1+k_{2}\right)-4 d^{2}\left(3+k_{1} k_{2}\right)\right]^{2}} \times \\
\times\left[d^{6}\left(1+k_{1}\right)\left(1+k_{2}\right)^{2}+d^{4}\left(8-28 k_{1}-24 k_{2}-4 k_{1} k_{2}^{2}\right)+d^{2}\left(80 k_{1}+32 k_{2}-16\right)-64 k_{1}\right]
\end{gathered}
$$

and

$$
\begin{aligned}
& \Delta_{2,2}^{B}=\frac{(1-d)\left[d^{2}-k_{2}\left(4-d^{2}\right)\right]\left[4-d^{2}\left(1+k_{1}\right)+2 d\left(1-k_{1}\right)\right]^{2}}{16(1+d)\left(2-d^{2}\right)^{2}\left[16+d^{4}\left(1+k_{1}\right)\left(1+k_{2}\right)-4 d^{2}\left(3+k_{1} k_{2}\right)\right]^{2}} \times \\
& \times\left[d^{6}\left(1+k_{2}\right)\left(1+k_{1}\right)^{2}+d^{4}\left(8-28 k_{2}-24 k_{1}-4 k_{2} k_{1}^{2}\right)+d^{2}\left(80 k_{2}+32 k_{1}-16\right)-64 k_{2}\right]
\end{aligned}
$$

The sign of $\Delta_{1,1}^{B}, \Delta_{1,2}^{B}, \Delta_{2,1}^{B}$ and $\Delta_{2,2}^{B}$ changes depending on the relative position of $k_{1}$ and $k_{2}$ for any given value of $d$. In either cases of product substitutability $(0 \leq d \leq 1)$ and complementarity $(-1 \leq d \leq 0)$, it holds for any $0 \leq k_{2}<k_{2, \Delta_{1,2}}^{C}(d)$ that (1.1) if $0 \leq k_{1}<k_{1, \Delta_{1,1}}^{C}(d)$ then $\Delta_{1,1}^{B}>0, \Delta_{2,1}^{B}<0$, $\Delta_{1,2}^{B}>0$ and $\Delta_{2,2}^{B}<0,(1.2)$ if $k_{1, \Delta_{1,1}}^{C}(d)<k_{1}<1$ then $\Delta_{1,1}^{B}<0, \Delta_{2,1}^{B}>0, \Delta_{1,2}^{B}>0$ and $\Delta_{2,2}^{B}>0$; for any $k_{2, \Delta_{1,2}}^{C}(d)<k_{2}<1$ that $(2.1)$ if $0 \leq k_{1}<k_{1, \Delta_{1,1}}^{C}(d)$ then $\Delta_{1,1}^{B}>0, \Delta_{2,1}^{B}>0, \Delta_{1,2}^{B}<0$ and $\Delta_{2,2}^{B}>0,(2.2)$ if $k_{1, \Delta_{1,1}}^{C}(d)<k_{1}<1$ then $\Delta_{1,1}^{B}<0, \Delta_{2,1}^{B}>0, \Delta_{1,2}^{B}<0$ and $\Delta_{2,2}^{B}>0$. Q.E.D.

As in the case of Cournot competition, it would be instructive to present a picture that summarises the equilibrium outcomes of a Bertrand competition game with asymmetric managerial behaviour. To that purpose, Figure B.2 shows the four regions of the Nash outcomes in $\left(k_{1}, k_{2}\right)$ space. Also in this case, the figure clearly reveals that the outcomes of the game with homogeneous managerial behaviour hold for several couples $\left(k_{1}, k_{2}\right)$. This is true even for large asymmetries between managers' strength in the bargaining, that is for values of $k_{1}$ and $k_{2}$ that are far ways from the straight line $k_{1}=k_{2}$. In conclusion, when both managers bargain moderately (small bargaining power), the owners of each firm delegate output decisions to CEO's. When both managers bargain aggressively (large bargaining power), the owners do not delegate output decision to CEO's and then play a standard Bertrand game without sales delegation. When only one of the two managers bargain aggressively, the Nash equilibrium is mixed and for the owner of the firm with an aggressive manager it is optimal to do not hire him. The figure is depicted for $d=0.9$ 
(substitutability) and $d=-0.9$ (complementarity) for reasons of expository clarity. Of course, it qualitatively holds for the whole range of values of the parameter capturing the extent of product differentiation, i.e. $-1 \leq d<1$.

With regard to Pareto efficiency, we limit ourselves to stress that when product are substitutes (resp. complements) all the equilibrium outcomes are efficient (resp. sub-optimal) in their own parametric space.

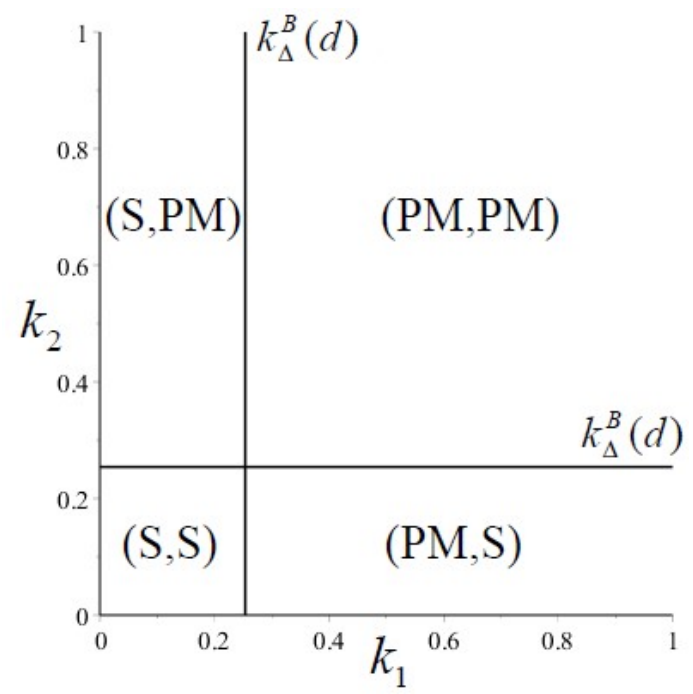

Figure B.2. The bargaining-sales-delegation game with asymmetric managerial behaviour. Profit differentials in $\left(k_{1}, k_{2}\right)$ space under Bertrand competition in the case of product substitutability $(d=0.9)$ and product complementarity $(d=-0.9)$.

\section{Appendix C. Endogenous managerial bargaining power}

This appendix further extends the model developed in the main text to answer a question that comes from the consideration that in actual markets there may exist various types of managers with different bargaining power (as also discussed in Appendix B). By accounting for this heterogeneity, we now study a model in which the owner of a firm chooses to hire a manager whose bargaining strength is exactly the one that maximises his profits. Then, let us first assume that there exists a continuum of managers $0<k_{i}<1$ that are differentiated between them depending on their relative attitude to bargain. The research question, which is novel at the best of our knowledge, arising in this context in the following: with this endogenous decision, do owners hire a manager who has no bargaining power (as one could believe at the first sight) or, alternatively, a positive bargaining power at the equilibrium with quantity and price competition? In other words, we will show that the strategic effects interacting with the degree of product differentiation (that is, with a degree of market power) may imply that, at the equilibrium, owners hire managers with a sizeable bargaining power.

Then, the stages of this game become the following. At stage 1 (the contract-bonus stage), firms strategically choose the nature of the bonus (pure profits or sales delegation). At stage 2 (the manager-strength stage), the owner of each firm chooses to hire a manager whose bargaining strength is exactly the one that maximises his profits. At stage 3 (the bargaining stage), owners and managers bargain over executive remuneration by maximising the Nash product (B.1). At stage 4 (the market stage), managers strategically choose either the quantity (in the case of quantity-setting behaviour) or the price (in the case of price-setting behaviour). 


\section{C.1. Cournot competition}

The main difference with respect to the model analysed in Appendix B is that in the case of uniform behaviour under sales delegation or in the case of mixed behaviour, firm $i$ chooses to hire a manager based on his own profits maximisation by considering $k_{i}$ as the control variable. Therefore, knowing the extent of both the quantity $q_{i}$ produced at the equilibrium and the incentive parameter $b_{i}$, owner $q_{i}$ maximises $\Pi_{i}$ with respect to $k_{i}$ given the choices of the rival (player $j$, $i, j=1,2, i \neq j$ ). The results of this maximisation programme (i.e., the optimal values of the bargaining power of the manager) in the cases of uniform and mixed behaviours are summarised Table C.1.

\begin{tabular}{|c|c|c|}
\hline Firm 1 Firm 2 & $\begin{array}{c}\text { PM } \\
\text { (Cournot) }\end{array}$ & $\begin{array}{c}\text { S } \\
\text { (Cournot) }\end{array}$ \\
\hline $\begin{array}{c}\text { PM } \\
\text { (Cournot) }\end{array}$ & $k_{1}^{P M / P M}, k_{2}^{P M / P M}$ & $k_{1}^{P M / S}, k_{2}^{P M / S}$ \\
\hline $\begin{array}{c}\text { S } \\
\text { (Cournot) }\end{array}$ & $k_{1}^{S / P M}, k_{2}^{S / P M}$ & $k_{1}^{S / S}, k_{2}^{S / S}$ \\
\hline
\end{tabular}

Table C.1. Optimal (profit-maximising) values of $k_{i}$ in the cases of uniform and mixed behaviours.

The entries of Table C.1 are the following.

$$
\begin{gathered}
k_{1}^{P M / P M}=k_{2}^{P M / P M}=0, \\
k_{1}^{S / S}=k_{2}^{S / S}=1+\frac{8\left(1-d^{2}\right)}{d^{4}}-\frac{4\left(2-d^{2}\right) \sqrt{1-d^{2}}}{d^{4}},
\end{gathered}
$$

where $0 \leq k_{i}^{S / S} \leq 1$ for any $-1 \leq d \leq 1$, and

$$
k_{1}^{S / P M}=k_{2}^{S / P M}=k_{1}^{P M / S}=k_{2}^{P M / S}=0 .
$$

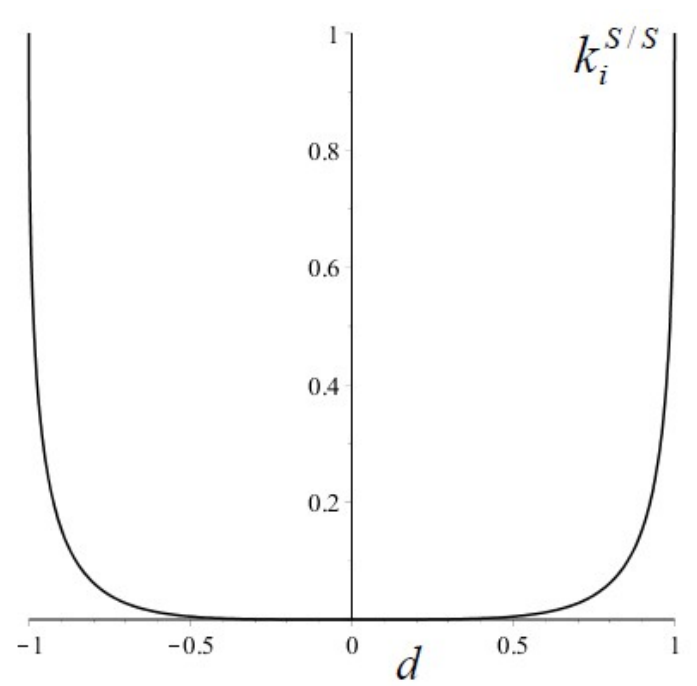

Figure C.1. Optimal value $k_{i}^{S / S}$ as a function of $d$.

Table C.1 reveals the existence of an optimal positive bargaining strength only when both firms are sales-delegated. The optimal value $k_{i}^{S / S}$ is an increasing function of the (absolute value of the) extent of product differentiation, as is shown in Figure C.1. As can be observed, this optimal value of $k$ is always included in the feasible range $(0,1)$ for all the meaningful values of parameter $d$. Indeed, as long as products tend to become sufficiently substitutes (resp. complements), the market 
power of each firm reduces. Therefore, managers should increase their effort in the bargaining to capture the benefits of sales delegation (resp. firms behave as if they colluded in the market so that managers have an incentive to increase their bargaining power to share the benefit of higher profits with the rival). In other words, an owner has an incentive to hire (unilaterally) a manager with a high degree of bargaining. This holds because the higher the bargaining power of the manager, the higher the aggressiveness of the manager in the market. Therefore, both owners will hire managers with a strong degree of bargaining at the equilibrium. In fact, each owner wants to avoid (unilaterally) producing a lower amount of goods than the rival thus getting lower profits. Definitely, each owner will endogenously hire the highest possible contractually strong manager, although this will reduce equilibrium profits in comparison with hiring managers with a lower degree of bargaining. Interestingly, this mechanism is very sensible to changes in the degree of product differentiation, and it will be weakened considerably even for very small increases in the degree of product differentiation. For example, with $d=0.99$ we have that $k_{i}^{S / S}=0.566$, whereas a small increase in product differentiation $d=0.9$ implies $k_{i}^{S / S}=0.154$.

Given this, the payoff matrix (profits of both firms) in the case of endogenous bargaining power is summarised in Table C.2.

\begin{tabular}{|c|c|c|}
\hline Firm 1 & $\begin{array}{c}\text { PM } \\
\text { (Cournot) }\end{array}$ & $\begin{array}{c}\text { S } \\
\text { (Cournot) }\end{array}$ \\
\hline $\begin{array}{c}\text { PM } \\
\text { (Cournot) }\end{array}$ & $\Pi_{1}^{P M / P M}, \Pi_{2}^{P M / P M}$ & $\Pi_{1}^{P M / S}, \Pi_{2}^{P M / S}$ \\
\hline $\begin{array}{c}\text { S } \\
\text { (Cournot) }\end{array}$ & $\Pi_{1}^{S / P M}, \Pi_{2}^{S / P M}$ & $\Pi_{1}^{S / S}, \Pi_{2}^{S / S}$ \\
\hline
\end{tabular}

Table C.2. Payoff matrix: profits under sales delegation (S) and profit maximisation (PM) with Cournot competition and heterogeneous managers in the case of endogenous managerial bargaining power.

The entries of Table C. 2 are the following.

$$
\begin{gathered}
\Pi_{1}^{P M / P M}=\Pi_{2}^{P M / P M}=\frac{1}{(2+d)^{2}}, \\
\Pi_{1}^{S / S}=\Pi_{2}^{S / S}=\frac{\left[\left(2-d^{2}\right) \sqrt{1-d^{2}}-2\left(1-d^{2}\right)\right]\left[2-d^{2}-2 \sqrt{1-d^{2}}\right]}{d^{2}\left[2+d(1-d)-(2+d) \sqrt{1-d^{2}}\right]^{2}}, \\
\Pi_{1}^{S / P M}=\Pi_{2}^{P M / S}=\frac{(2-d)^{2}}{8\left(2-d^{2}\right)}, \\
\Pi_{1}^{P M / S}=\Pi_{2}^{S / P M}=\frac{[4-d(2+d)]^{2}}{16\left(2-d^{2}\right)^{2}} .
\end{gathered}
$$

The following proposition holds.

Proposition C.1. (a) [Cournot - product substitutability $(0 \leq d \leq 1)$ ]. (1) Let $0 \leq d<0.7691$ hold. Then, (S,S) is the unique sub-optimal SPNE of the game. (2) Let $0.7691<d \leq 1$ hold. Then, there exist two pure-strategy asymmetric Nash equilibria, that is $(\mathrm{S}, \mathrm{PM})$ and $(\mathrm{PM}, \mathrm{S})$. Both equilibria are Pareto efficient.

(b) [Cournot - product complementarity $(-1 \leq d \leq 0)$ ]. Let $-1 \leq d<0$ hold. Then, (S,S) is the unique Pareto efficient SPNE of the game.

Proof. Profit differentials are the following. 


$$
\begin{gathered}
\Delta_{1}^{C}=\frac{d^{4}}{8\left(2-d^{2}\right)(2+d)^{2}}>0, \\
\Delta_{2}^{C}=\frac{\left[d^{2}\left(d^{7}-3 d^{6}-4 d^{5}+56 d^{4}-256 d^{2}+448\right)-256\right] \sqrt{1-d^{2}}-3 d^{9}+17 d^{8}+4 d^{7}-144 d^{6}+448 d^{4}-576 d^{2}+256}{8 d^{2}\left(2-d^{2}\right)^{2}\left[2+d(1-d)-(2+d) \sqrt{1-d^{2}}\right]^{2}}
\end{gathered}
$$

and

$$
\Delta_{3}^{C}=\frac{-\sqrt{1-d^{2}}\left(d^{6}+2 d^{5}-6 d^{4}-24 d^{3}-16 d^{2}+32 d+32\right)+32+32 d-32 d^{2}-40 d^{3}-2 d^{4}+10 d^{5}+4 d^{6}}{d^{2}(2+d)^{2}\left[2+d(1-d)-(2+d) \sqrt{1-d^{2}}\right]^{2}},
$$

where $\Delta_{3}^{C}>0$ for any $0 \leq d \leq 1$ (resp. $\Delta_{3}^{C}<0$ for any $-1 \leq d \leq 0$ ). The sign of $\Delta_{2}^{C}$ changes depending on the relative position of $d$. Then, under product substitutability $(0 \leq d \leq 1)$, it holds that (1) $\Delta_{1}^{C}>0, \quad \Delta_{2}^{C}<0 \quad$ and $\quad \Delta_{3}^{C}>0 \quad$ for any $0 \leq d<0.7691 ; \quad$ (2) $\Delta_{1}^{C}>0, \quad \Delta_{2}^{C}>0 \quad$ and $\Pi_{i}^{S / P M}>\Pi_{i}^{P M / P M}>\Pi_{i}^{P M / S}>\Pi_{i}^{S / S}$ for any $0.7691<d \leq 1$. Under product complementarity $(-1 \leq d \leq 0)$, it holds that $\Delta_{1}^{C}>0, \Delta_{2}^{C}<0$ and $\Delta_{3}^{C}<0$ for any $-1 \leq d \leq 0$. Q.E.D.

Proposition C. 1 suggests that the outcome of a bargaining-sales-delegation game with endogenous managerial strength is $(\mathrm{S}, \mathrm{S})$ for a wide range of values of the extent of product differentiation in either cases of product complementarity and substitutability. This implies that the owner of each firm delegates output decisions to a manager with a positive bargaining strength, which is exactly the one that maximises owner's profits (see Table C.1). This happens as each owner wants to hire a manager according to an optimal rule. Then there is an increase in output for both firms so that no one has a unilateral incentive to deviate from S. In line with VFJS's result, $(\mathrm{S}, \mathrm{S})$ is sub-optimal (prisoner's dilemma) when products are substitutes and efficient when product are complements. However, when products tend to become homogeneous (as in the original contributions of VFJS), there are multiple mixed (efficient) Nash equilibria corresponding to which only one of the firms delegates output decisions to a manager but without any negotiation over weight $b_{i}$ (which is determined by the owner unilaterally), whereas the rival behaves just like a profit maximiser. Then, when products are sufficiently substitutes between each other, the game becomes a noncoordination game in which no one has a dominant strategy and both equilibria are Pareto optimal. This is because both players should adopt the opposite strategy to that of his rival. Of course, each player prefers one of the two equilibria. The solution of the game comes from the credible disclosure of a player's will to do not play S. Then, the rival will be forced to (be the first to) play $\mathrm{S}$ to avoid obtaining a lower payoff unilaterally. A non-cooperation game just like the present one differs from a prisoner's dilemma typical of the literature à la VFJS to the fact that the worst possible outcome for both participants occurs after a mutual willingness to delegate. If one player plays PM unilaterally, he gets the second worst result. On the contrary, mutual deviation in a prisoner's dilemma leads to the second worst result, and the individual will to cooperate supports the worst case.

\section{C.2. Bertrand competition}

Under Bertrand competition, the results of owners' profits maximisation with respect to the bargaining power of the managers implies that $k_{i}=0$ in all cases of uniform and mixed behaviours.

This means the owner of every price-setting firm finds it optimal to do not bargain with a manager to set the incentive parameter $b_{i}$. Therefore, the payoff matrix that summarises profit outcomes under S and PM is reported in Table C.3. 


\begin{tabular}{|c|c|c|}
\hline Firm 2 & $\begin{array}{c}\text { PM } \\
\text { (Bertrand) }\end{array}$ & $\begin{array}{c}\text { S } \\
\text { (Bertrand) }\end{array}$ \\
\hline $\begin{array}{c}\text { PM } \\
\text { (Bertrand) }\end{array}$ & $\Pi_{1}^{P M / P M}, \Pi_{2}^{P M / P M}$ & $\Pi_{1}^{P M / S}, \Pi_{2}^{P M / S}$ \\
\hline $\begin{array}{c}\text { S } \\
\text { (Bertrand) }\end{array}$ & $\Pi_{1}^{S / P M}, \Pi_{2}^{S / P M}$ & $\Pi_{1}^{S / S}, \Pi_{2}^{S / S}$ \\
\hline
\end{tabular}

Table C.2. Payoff matrix: profits under sales delegation (S) and profit maximisation (PM) with Bertrand competition and heterogeneous managers in the case of endogenous managerial bargaining power.

The entries of Table C.3 are the following.

$$
\begin{gathered}
\Pi_{1}^{P M / P M}=\Pi_{2}^{P M / P M}=\frac{(1-d)^{2}}{\left(1-d^{2}\right)(2-d)^{2}}, \\
\Pi_{1}^{S / S}=\Pi_{2}^{S / S}=\frac{2(1-d)\left(2-d^{2}\right)\left(4+2 d-d^{2}\right)^{2}}{(1+d)\left(16+d^{4}-12 d^{2}\right)^{2}}, \\
\Pi_{1}^{S / P M}=\Pi_{2}^{P M / S}=\frac{(1-d)(2+d)^{2}}{8(1+d)\left(2-d^{2}\right)} \\
\Pi_{1}^{P M / S}=\Pi_{2}^{S / P M}=\frac{(1-d)\left(4+2 d-d^{2}\right)^{2}}{16(1+d)\left(2-d^{2}\right)^{2}} .
\end{gathered}
$$

The following proposition holds.

Proposition C.2. (a) [Bertrand - product substitutability $(0 \leq d \leq 1)$ ]. $(\mathrm{S}, \mathrm{S})$ is the unique Pareto efficient SPNE of the game for any $0 \leq d \leq 1$.

(b) [Bertrand - product complementarity $(-1 \leq d \leq 0)]$. $(\mathrm{S}, \mathrm{S})$ is the unique sub-optimal SPNE of the game for any $-1 \leq d \leq 0$.

Proof. Profit differentials are the following.

$$
\begin{gathered}
\Delta_{1}^{B}=\frac{d^{4}(1-d)}{8(1+d)\left(2-d^{2}\right)(2-d)^{2}}>0, \\
\Delta_{2}^{B}=\frac{-d^{4}(1-d)\left(16-d^{4}-8 d^{2}\right)}{16(1+d)\left(2-d^{2}\right)^{2}\left(4-d^{2}-2 d\right)^{2}}<0
\end{gathered}
$$

and

$$
\Delta_{3}^{B}=\frac{-d^{3}(1-d)(4-3 d)}{(1+d)(2-d)^{2}\left(4-d^{2}-2 d\right)^{2}},
$$

where $\Delta_{3}^{B}<0$ for any $0 \leq d \leq 1$ (resp. $\Delta_{3}^{B}>0$ for any $-1 \leq d \leq 0$ ). Then, under product substitutability $(0 \leq d \leq 1)$, it holds that $\Delta_{1}^{B}>0, \Delta_{2}^{B}<0$ and $\Delta_{3}^{B}<0$ for any $0 \leq d \leq 1$. Under product complementarity $(-1 \leq d \leq 0)$, it holds that $\Delta_{1}^{B}>0, \Delta_{2}^{B}<0$ and $\Delta_{3}^{B}>0$ for any $-1 \leq d \leq 0$. Q.E.D.

In contrast with the case of Cournot competition, the result emerging from Proposition C. 2 is that each owner finds it optimal to delegate price decisions to a manager who has no bargaining over the incentive parameter. This holds for the whole range of values of the extent of product differentiation. Then, under Bertrand competition, the "classical" VFJS's results also hold when owners may choose endogenously the type (and then the power) of their managers. 
The bargaining-sales-delegation game

\section{References}

Aguilera RV, Cuervo-Cazurra A. 2004. Codes of good governance worldwide: what is the trigger? Organization Studies 25: 415-443.

Aoki M. 1980. A model of the firm as a stockholder employee cooperative game. American Economic Review 70: 600-610.

Baumol W. 1958. On the theory of oligopoly. Economica 25: 187-198.

Bebchuk LA, Fried JM. 2003. Executive compensation as an agency problem. Journal of Economic Perspectives 17: 71-92.

Bebchuk LA, Fried JM. 2004. Pay without Performance. The Unfulfilled Promise of Executive Compensation. Cambridge (MA) US: Harvard University Press.

Bebchuk LA, Grinstein Y. 2005. The growth of executive pay. Oxford Review of Economic Policy 21: 283-303.

Berr F. 2011. Stackelberg equilibria in managerial delegation games. European Journal of Operational Research 212: 251-262.

Bhattacharjee T, Pal R. 2013. Network externalities and strategic managerial delegation in Cournot duopoly: is there a prisoners' dilemma? Review of Network Economics 12: 343-353.

Binmore K, Rubinstein A, Wolinsky A. 1986. The Nash bargaining solution in economic modelling. RAND Journal of Economics 17: 176-188.

Bughin J. 1995. Unions and strategic managerial incentives. Economics Letters 47: 95-100.

Chirco A, Scrimitore M. 2013. Choosing price or quantity? The role of delegation and network externalities. Economics Letters 121: 482-486.

Correa-López M, Naylor RA. 2004. The Cournot-Bertrand profit differential: a reversal result in a differentiated duopoly with wage bargaining. European Economic Review 48: 681-696.

Cyert R, March J. 1963. Behavioral Theory of the Firm. Englewood Cliffs (NJ) US: Prentice-Hall.

Dixit AK. 1979. A model of duopoly suggesting a theory of entry barriers. Bell Journal of Economics 10: 20-32.

Englmaier F. 2011. Commitment in R\&D tournaments via strategic delegation to overoptimistic managers. Managerial and Decision Economics 32: 63-69.

Fanti L, Meccheri M. 2015. A note on managerial delegation with asymmetric and convex costs. Managerial and Decision Economics, forthcoming.

Fershtman C. 1985. Managerial incentives as a strategic variable in duopolistic environment. International Journal of Industrial Organization 3: 245-253. 
Fershtman C, Judd KL. 1987. Equilibrium incentives in oligopoly. American Economic Review 77: 927-940.

Häckner J. 2000. A note on price and quantity competition in differentiated oligopolies. Journal of Economic Theory 93: 233-239.

Inderst R. 2002. Contract design and bargaining power. Economics Letters 74: 171-176.

Jansen T, van Lier A, van Witteloostuijn A. 2007. A note on strategic delegation: the market share case. International Journal of Industrial Organization 25: 531-539.

Jansen T, van Lier A, van Witteloostuijn A. 2009. On the impact of managerial bonus systems on firm profit and market competition: the cases of pure profit, sales, market share and relative profits compared. Managerial and Decision Economics 30: 141-153.

Jansen T, van Lier A, van Witteloostuijn A. 2012. Managerial bonus systems in a differentiated duopoly: a comment. Managerial and Decision Economics 33: 61-70.

Jensen MC Murphy KJ. 1990. Performance pay and top management incentives. Journal of Political Economy 98: 225-264.

Kamaga K, Nakamura Y. 2008. Bargaining over managerial contracts in delegation games: the sequential move case. Economics Bulletin 12: 1-8.

Kopel M, Pezzino M, Ressi A. 2016. Location choice and contract bargaining. Managerial and Decision Economics 37: 140-148.

Lambert RA, Larcker DF, Weigelt K. 1991. How sensitive is executive compensation to organizational size. Strategic Management Journal 12: 395-402.

Laux V, Mittendorf B. 2011. Board independence, executive pay, and the adoption of pet projects. Contemporary Accounting Research 28: 1467-1483.

Leibenstein H. 1979. A branch of economics is missing: micro-micro theory. Journal of Economic Literature 17: 477-502.

Manasakis C, Mitrokostas E, Petrakis E. 2011. Endogenous managerial incentive contracts in a differentiated duopoly, with and without commitment. Managerial and Decision Economics 31: $531-543$.

Mazzeo MJ. 2002. Competitive outcomes in product-differentiated oligopoly. Review of Economics and Statistics 84: 716-728.

Merzoni GS. 2003. Strategic Delegation in Firms and the Trade Union. Berlin: Springer.

Miller N, Pazgal A. 2002. Relative performance as a strategic commitment mechanism. Managerial and Decision Economics 23: 51-68.

Mujumdar S, Pal D. 2007. Strategic managerial incentives in a two-period Cournot duopoly. Games and Economic Behavior 58: 338-353. 
Nakamura Y. 2008a. Bargaining over managerial contracts in delegation games: the differentiated goods case. Economics Bulletin 12: 1-8.

Nakamura Y. 2008b. Bargaining over managerial contracts in delegation games: the quadratic cost case. Economics Bulletin 12: 1-7.

Nakamura Y. 2011. Bargaining over managerial delegation contracts and merger incentives with asymmetric costs. Manchester School 79: 718-739.

Nakamura Y. 2012. Bargaining over managerial contracts in delegation games: the generalized oligopolistic case. Managerial and Decision Economics 33: 249-272.

Nash JF. 1950. The bargaining problem. Econometrica 28: 155-162.

Ritz RA. 2008. Strategic incentives for market share. International Journal of Industrial Organization 26: 586-597.

Roth AE. 1979. Axiomatic models of bargaining. Lecture notes in economics and mathematical systems 170, Berlin: Springer.

Salas Fumás V. 1992. Relative performance evaluation of management. International Journal of Industrial Organization 10: 473-489.

Simon HA. 1964. On the concept of organizational goal. Administrative Science Quarterly 9: 1-21.

Singh N, Vives X. 1984. Price and quantity competition in a differentiated duopoly. RAND Journal of Economics 15: 546-554.

Sklivas SD. 1987. The strategic choice of managerial incentives. RAND Journal of Economics 18: $452-458$.

Szymanski S. 1994. Strategic delegation with endogenous costs. A duopoly with wage bargaining. International Journal of Industrial Organization 12: 105-116.

van Witteloostuijn A. 1998. Bridging behavioral and economic theories of decline: organizational inertia, strategic competition, and chronic failure. Management Science 44: 501-519.

van Witteloostuijn A, Jansen T, van Lier A. 2007. Bargaining over managerial contracts in delegation games: managerial power, contract disclosure and cartel behaviour. Managerial and Decision Economics 28: 897-904.

Vickers J. 1985. Delegation and the theory of the firm. Economic Journal 95: 138-147.

Wang LFS, Wang YC, Zhao W. 2008. Strategic trade policy in bargaining over managerial delegation competition. Economics Bulletin 6: 1-8.

Williamson OE. 1964. The Economics of Discretionary Behavior: Managerial Objectives in a Theory of the Firm. Englewood Cliffs (NJ) US: Prentice-Hall. 